\title{
The lysosomal V-ATPase B1 subunit in proximal tubule is linked to nephropathic cystinosis
}

Amer Jamalpoor ${ }^{1}$, Albertien M van Eerde ${ }^{2}$, Marc R Lilien ${ }^{3}$, Charlotte AGH van Gelder ${ }^{4,5}$, Esther A Zaal ${ }^{4}$, Floris A Valentijn ${ }^{6}$, Roel Broekhuizen ${ }^{6}$, Eva Zielhuis $^{1}$, Julia E Egido ${ }^{1}$, Maarten Altelaar ${ }^{4,5}$, Celia R Berkers ${ }^{4,7}$, Rosalinde Masereeuw ${ }^{1}$, and Manoe J Janssen ${ }^{1 *}$

${ }^{1}$ Utrecht Institute for Pharmaceutical Sciences, Division of Pharmacology, Utrecht, The Netherlands. ${ }^{2}$ Department of Genetics, University Medical Centre Utrecht, Utrecht, the Netherlands. ${ }^{3}$ Department of Pediatric Nephrology, Wilhelmina Children's Hospital, University Medical Centre Utrecht, Utrecht, the Netherlands. ${ }^{4}$ Biomolecular Mass Spectrometry and Proteomics, Bijvoet Center for Biomolecular Research and Utrecht Institute for Pharmaceutical Sciences, Utrecht University, Utrecht, The Netherlands. ${ }^{5}$ Netherlands Proteomics Center, Utrecht, The Netherlands. ${ }^{6}$ Department of Pathology, University Medical Centre Utrecht, Utrecht, the Netherlands. ${ }^{7}$ Division of Cell Biology, Metabolism \& Cancer, Department of Biomolecular Health Sciences, Faculty of Veterinary Medicine, Utrecht University, Utrecht, The Netherlands.

\section{*Corresponding author:}

Manoe J Janssen, Utrecht Institute for Pharmaceutical Sciences, Division of Pharmacology, Utrecht, The Netherlands. Email: m.j.janssen1@uu.nl.

\section{Keywords:}

Renal tubular acidosis, cystinosis, cystine accumulation, autophagy, renal Fanconi syndrome 


\begin{abstract}
Background. Recently, a 23-month-old girl presented with increased granulocyte cystine levels, metabolic acidosis and symptoms of renal Fanconi syndrome. Cystinosis was suspected and treatment with electrolytes and cysteamine, a cystine depleting agent, was started that appeared effective. However, genetic testing did not detect any variants in CTNS (the gene affected in cystinosis) but instead revealed pathogenic variants in ATP6V1B1. ATP6V1B1 encodes the B1 subunit of the vacuolar $\mathrm{H}^{+}$-ATPase (V-ATPase), that is linked to autosomal recessive distal renal tubular acidosis, a metabolic disorder with an inappropriately alkaline urine and deafness. Here, the unknown link between ATP6V1B1 gene deficiency and proximal tubulopathy as well as a possible link to cystinosis pathophysiology was investigated.
\end{abstract}

Methods. We used CRISPR/Cas9 technology to selectively knockout the ATP6V1B1 or CTNS gene in human renal proximal tubule cells and compare their proteomic and metabolomic profile with isogenic wild type proximal tubule cells.

Results. ATP6V1B1 was expressed along the human distal but also the proximal segments of the nephron. Consistent with the clinical data, loss of ATP6V1B1 in renal proximal tubule cells resulted in increased cystine levels with autophagy activation. Further, omics profiling showed that both $A T P 6 V 1 B 1^{--}$and $\mathrm{CTNS}^{\text {\%- }}$ cells are in metabolic acidosis with impaired autophagy and signs of proximal tubular epithelial dysfunction.

Conclusion. We identified the lysosomal V-ATPase B1 subunit to play an important role in proximal tubule function, regulating cystine transport and autophagy in human renal proximal tubule cells through its interaction with cystinosin and mTOR-signaling. 


\section{Introduction}

A 23-month-old girl presented with increased granulocyte cystine levels, metabolic acidosis and signs of renal Fanconi syndrome. The patient was diagnosed with nephropathic cystinosis and treatment with cysteamine, a cystine depleting agent, and electrolytes were started that improved the patient's clinical conditions. Nephropathic cystinosis (MIM_219800) is an autosomal recessive lysosomal storage disease caused by pathogenic variants in the CTNS gene, which encodes the lysosomal $\mathrm{H}^{+}$/cystine symporter, cystinosin. ${ }^{1}$ The disease is characterized by the accumulation of cystine throughout the body, causing irreversible damage to various organs, particularly the kidneys. ${ }^{2}$ Clinically, nephropathic cystinosis patients first develop renal Fanconi syndrome, a general renal proximal tubular dysfunction characterized by the presence of phosphaturia, glucosuria, impaired bicarbonate reabsorption and generalized aminoaciduria. ${ }^{2,3}$ With time, this leads to other complications such as growth retardation, rickets, and chronic kidney disease. The main treatment option currently available is cysteamine, an aminothiol that reduces cystine by converting it into cysteine and cysteine-cysteamine mixed disulfide, both of which are able to exit the lysosomes. ${ }^{4}$ Although this drug is found effective in depleting cystine, it is not efficient to revert the signs associated with renal Fanconi syndrome. ${ }^{5}$

After starting treatment with cysteamine in this patient, the cystine levels dropped below the reference level, which is considered very unusual for any patient with nephropathic cystinosis. This prompted diagnostic renal gene panel sequencing and the analysis revealed pathogenic variants in the ATP6V1B1 gene (NM_001692.3), while the CTNS gene was found to be intact. The ATP6V1B1 gene codes for the kidney isoform of the B1 subunit of the V1 domain of the vacuolar $\mathrm{H}^{+}$-ATPase (V-ATPase; ATP6V1B1), responsible for acidification of intracellular organelles and 
renal acid-base homeostasis. Variants in this gene lead to autosomal recessive distal renal tubular acidosis (dRTA) with sensorineural deafness ${ }^{6,7}$ and its relevance are therefore widely characterized in the distal tubule. ${ }^{8-10}$ However, another case has been described in which two siblings with distal renal tubular acidosis and ATP6V1B1 gene variants displayed proximal tubular dysfunction, suggesting a role for this gene in the proximal tubule as well. ${ }^{11}$

Both ATP6V1B1 and cystinosin can be found on the lysosomal membrane of kidney cells and may work together in several ways. As a subunit of the V-ATPase, ATP6V1B1 is thought to play a role in lysosome acidification, which in turn is important for the function of cystinosin which depends on this proton gradient for the export of protons and cystine from the lysosome into the cytosol. $^{12,13}$ Besides this chemiosmotic coupling, both cystinosin and the V-ATPase complex closely interacts with mammalian target of rapamycin complex 1 (mTORC1), regulating autophagy. ${ }^{12,14,15}$ Intriguingly, different variants of V-ATPases are also found to regulate transcription factor EB (TFEB), a master regulator of autophagy, ${ }^{16}$ whose function is also dysregulated in cystinosis. ${ }^{17,18}$

In this study, we therefore aimed to investigate the role of the B1 subunit of the lysosomal VATPase in proximal tubules and compare ATP6V1B1 loss to CTNS loss, which is the most common cause of renal Fanconi syndrome in children and has been well studied in proximal tubule cells. We developed CRISPR-generated ATP6V1B1-deficient proximal tubule cells, serving as a disease model, and compared their phenotype to well-characterized isogenic CTNS $^{-/}$cells. ${ }^{17}$ Furthermore, we applied a dual-omics approach, combining proteomics and metabolomics, to bridge the gap between the ATP6V1B1 gene defect and cystinosis, with the future aim of better understanding the disease mechanism and finding druggable targets. 


\section{Methods}

\section{Reagent}

All chemicals and reagents were obtained from Sigma-Aldrich (Zwijndrecht, The Netherlands) unless specified otherwise. Primary antibodies used were rabbit anti-ATP6V1B1 (Abcam \#ab192612, dilution 1:500) and mouse anti-LC3 (Novus Biologicals \#NB600-1384SS, dilution 1:1000). Secondary antibodies used were goat anti-rabbit BrightVision Horse Radish Peroxidase (Klinipath, Duiven, The Netherlands) and goat anti-mouse (\#A32723, dilution 1:5000) obtained from Dako products (CA, USA).

\section{Immunohistochemistry on human renal tissue sections}

A normal human kidney tissue section was derived from tumor free kidney of a patient undergoing nephrectomy for renal carcinoma at the University Medical Center Utrecht (UMCU). The patient sample was anonymized. Because leftover material from routine clinical procedures in the UMCU was used, informed patient consent and additional ethical approval were not required. The UMCU policy allows anonymous use of redundant tissue for research purposes as part of the standard treatment agreement with patients in the UMCU. ${ }^{19}$ Renal tissue was fixed in a $4 \%$ buffered formalin solution for $24 \mathrm{hrs}$ and subsequently embedded in paraffin blocks. Sections of $3 \mu \mathrm{m}$ were cut and mounted on adhesive slides (Leica Xtra) and rehydrated through a series of xylene and alcohol washes after which slides were rinsed in distilled water. First endogenous peroxidase was blocked using $\mathrm{H}_{2} \mathrm{O}_{2}$. This was followed by heat-based antigen retrieval in citrate buffer $(\mathrm{pH} \mathrm{6)}$ and primary antibody incubation (anti-ATP6V1B1, Abcam ab192612, 1:500) diluted in PBS/1\%BSA. After incubation with goat anti-rabbit BrightVision Horse Radish Peroxidase linked secondary antibody (Klinipath, Duiven, The Netherlands), sections were 
stained using Nova Red substrate (Vector Laboratories, Burlingame, CA, USA) and counterstained with Mayer's haematoxylin. Images were acquired using a Nikon Eclipse E800 microscope.

\section{CiPTEC culture}

The conditionally immortalized proximal tubular epithelial cells (ciPTEC) (MTA \#A16-0147) were obtained from Cell4Pharma (Nijmegen, The Netherlands) and were cultured as described previously by Wilmer et al. 2010. ${ }^{20}$ These cells have been immortalized using the temperature sensitive SV40ts A58 and human telomerase gene (hTERT), which allows them to be expanded at $33^{\circ} \mathrm{C}$ and regain a mature phenotype after culturing at $37^{\circ} \mathrm{C}$. The culture medium was Dulbecco's modified Eagle medium DMEM/F-12 (GIBCO) supplemented with fetal calf serum 10\% (v/v), insulin $5 \mu \mathrm{g} / \mathrm{ml}$, transferrin $5 \mu \mathrm{g} / \mathrm{ml}$, selenium $5 \mu \mathrm{g} / \mathrm{ml}$, hydrocortisone $35 \mathrm{ng} / \mathrm{ml}$, epidermal growth factor $10 \mathrm{ng} / \mathrm{ml}$ and tri-iodothyronine $40 \mathrm{pg} / \mathrm{ml}$. In short, cells were seeded at a density of 55,000 cells $/ \mathrm{cm}^{2}$ and grown at $33^{\circ} \mathrm{C}$ for $24 \mathrm{hrs}$ to enable them to proliferate and subsequently cultured at $37^{\circ} \mathrm{C}$ for 7 days to mature into fully differentiated tubular epithelial cells.

\section{Generation of $A T P 6 V 1 B 1^{\%}$ and CTNS $^{-/-}$isogenic ciPTEC lines}

We previously created an isogenic CRISPR-mediated cystinotic ciPTEC line, ${ }^{17}$ which will be referred to as $\mathrm{CTNS}^{-/}$. Using a low passage of the same parent ciPTEC line we created the ATP6V1B1 ${ }^{-/}$cell line as outlined. Guide RNAs (gRNAs) targeting exon 4 of the ATP6V1B1 gene were designed using the online gRNA designing tool available at chopchop.cbu.uib.no. To maximize specificity, guide sequences with high scores for on-target efficiency and no predicted off-targets having at least 3 base pair mismatches in the genome were selected. Optimal gRNA (5'-CCTACGAACTCCGGTGTCAG-3') was cloned into the pSPCas9(BB)-2A-GFP plasmid (Addgene 
\#48138) as described previously by Ran et al., ${ }^{21}$ and introduced into ciPTEC using PolyPlus JetPrime. 72 hrs post-transfection, GFP-positive singlet cells were sorted using FACS Aria-Il flow cytometer and expanded in 96-wells plate. The gRNA cut site was amplified with PCR using the primers flanking the cut region (F. ATP6V1B1_ex4 5'-ACTCTGAAGGCAGGAAATGGTC-3; R .ATP6V1B1_ex4 5'-GAGGAAGGTGGGTTCAATAAC-3'). Knockouts were finally confirmed by Sanger sequencing.

\section{Intracellular cystine quantification by HPLC-MS/MS}

Cystine levels were quantified using high-performance liquid chromatography-tandem mass spectrometry (HPLC-MS/MS); a rapid and sensitive assay that has been developed and validated

in house. ${ }^{22}$ In brief, cell pellets were suspended in N-Ethylmaleimide (NEM) solution containing $5 \mathrm{mM}$ NEM in $0.1 \mathrm{mM}$ sodium phosphate buffer $(\mathrm{pH} 7.4)$. The cell suspension was then precipitated, and protein was extracted with sulfosalicylic acid $15 \%(\mathrm{w} / \mathrm{v})$ and centrifuged at $20,000 \mathrm{~g}$ for $10 \mathrm{~min}$ at $4^{\circ} \mathrm{C}$. Protein concentration was determined by the method of the Pierce ${ }^{\mathrm{TM}}$ BCA protein assay kit according to the manufacturer's protocol (Thermo Fisher, The Netherlands), and the cystine concentration was measured using HPLC-MS/MS. Data are expressed as the cystine values (nmol) corrected for protein content $(\mathrm{mg})$.

\section{Quantitative real-time PCR}

The mRNAs were extracted from cells using the Qiagen RNeasy mini kit according to the manufacturer's instructions. Total mRNA (600 ng) was reverse transcribed using iScript Reverse Transcriptase Supermix (Bio-Rad). Quantitative real-time PCR was performed using iQ Universal SYBR Green Supermix (Bio-Rad) with the specific sense and anti-sense primers for ATP6V1B1 
(forward: 5'-TGGATATCAATGGCCAGCCC-3'; reverse: 5'-CTTCGCCATCGTCTTTGCAG-3'), CTNS

(forward: 5'-AGCTCCCCGATGAAGTTGTG-3'; reverse: 5'-GTCAGGTTCAGAGCCACGAA-3'), and TFEB (forward: 5'-GCAGTCCTACCTGGAGAATC-3'; reverse: 5'- TGGGCAGCAAACTTGTTCC-3'). The ribosomal protein S13 (RPS-13) (forward: 5'-GCTCTCCTTTCGTTGCCTGA-3'; reverse: 5'ACTTCAACCAAGTGGGGACG-3') was used as the reference gene for normalization and relative expression levels were calculated as fold change using the $2^{-\Delta \Delta} C t$ method.

\section{Immunofluorescence and confocal microscopy}

To investigate LC3-II accumulation, cells were seeded in a special optic 96-well plate in presence of $25 \mathrm{nM}$ bafilomycin (BafA1) for $4 \mathrm{hrs}$. Thereafter, cells were fixed with $4 \%$ paraformaldehyde in phosphate buffered saline (PBS) for $10 \mathrm{~min}$, permeabilized with $0.1 \%$ Triton-X solution for $10 \mathrm{~min}$, and blocked with $1 \%$ bovine serum albumin (BSA) diluted in PBS for 30 min. Subsequently, cells were stained with the primary antibody (mouse anti-LC3, dilution 1:1000) diluted in blocking buffer overnight at $4^{\circ} \mathrm{C}$. After 3 washes with PBS, the cells were incubated for 2 hrs at room temperature with the secondary antibody (goat anti-mouse, dilution 1:5000). Nuclei were stained with Hoechst $33342(1 \mu \mathrm{M})$ and cells were imaged using a Cell Voyager 7000 (CV7000) confocal microscope (Yokogawa Electric corporation, Tokyo, Japan).

To assess TFEB intracellular distribution, cells were seeded in a special optic 96-well plate until reaching $50 \%$ confluence. Cells were then transfected with the TFEB-GFP plasmid (a kind gift from Dr. Annelies Michiels (Viral Vector Core, Leuven, Belgium)) using PolyPlus JetPrime reagent according to the manufacturer's instructions. After $48 \mathrm{hrs}$ from transient transfection, cells were stained with Hoechst $33342(1 \mu \mathrm{M})$ for 10 min and imaged using a Cell Voyager 7000 (CV7000) confocal microscope (Yokogawa Electric corporation, Tokyo, Japan). TFEB nuclear translocation 
data are expressed as number of cells with nucleus-TFEB positive over the total number of TFEBtransfected cells.

\section{Endocytosis assay}

The endocytic uptake was monitored in ciPTEC following incubation for $1.5 \mathrm{hr}$ at $37^{\circ} \mathrm{C}$ with $50 \mu \mathrm{g} / \mathrm{ml}$ of either BSA-AlexaFluor-647 (A34785, Thermo Fisher Scientific) or DQ Red BSA (D12051, Invitrogen). The cells were then fixed and stained with Hoechst 33342 (1 $\mu \mathrm{M})$ for 10 min and imaged using a CV7000 confocal microscope (Yokogawa Electric corporation, Tokyo, Japan). Data were quantified with Columbus ${ }^{\mathrm{TM}}$ Image Data Storage and analysis software (PerkinElmer, Groningen, The Netherlands). Data are expressed as the number of BSA/DQ Red BSA spots per cell.

\section{Metabolomics and Proteomics}

The omics analyses were performed using high performance liquid chromatography mass spectrometry (HPLC/MS) and the data were analyzed as described previously. ${ }^{17}$

\section{Ethical Approval}

For the clinical case presented here appropriate informed consent was obtained from the parents of the patient for the publication of the anonymized data. Immunohistochemistry was performed on leftover material from routine clinical procedures in the UMCU, for which informed patient consent and additional ethical approval were not required.

\section{Statistical analysis}

Statistical analysis was performed using GraphPad Prism 7.0 (GraphPad Software, Inc., USA). Data are presented as mean \pm standard error of the mean (SEM) of at least three independent 
bioRxiv preprint doi: https://doi.org/10.1101/2020.07.24.219808; this version posted July 25, 2020. The copyright holder for this preprint (which was not certified by peer review) is the author/funder. All rights reserved. No reuse allowed without permission.

experiments performed in triplicate, unless stated otherwise. Significance was evaluated using One-way Analysis of Variance (ANOVA), or where appropriate unpaired two-tailed Student's ttest was applied. P-values $<0.05$ were considered significant. 


\section{Results}

\section{Patient with ATP6V1B1 variants displays a cystinosis-like phenotype of increased cystine levels,} metabolic acidosis and symptoms of renal Fanconi syndrome. A 23-month-old girl presented with symptoms of failure to thrive (height Z-score of -2.5 and weight Z-score of -2), and abnormal gait. The patient had impaired hearing from infancy. This was attributed to an enlarged vestibular aqueduct, demonstrated by CAT-scan at the age of four months.

Upon physical examination, she showed plump knee joints with varus deformity. Laboratory examination showed a normal anion-gap metabolic acidosis, hypokalemia, hypophosphatemia, generalized aminoaciduria and elevated cystine levels in granulocytes (Table 1). Renal ultrasound showed bilateral medullary hyper echogenicity and conventional X-ray examination of the knees showed epiphyseal fraying and cupping deformity. Based on the clinical and laboratory findings, the diagnosis of renal rickets due to generalized proximal tubular dysfunction (renal Fanconi syndrome) as a result of nephropathic cystinosis was made. Supplementation with potassium citrate, sodium phosphate, alfacalcidol (active vitamin D) and cysteamine bitartrate (Cystagon ${ }^{\circledR}$ ) was started. This resulted in an improvement of the patient's clinical conditions. However, diagnostic sequencing and multiplex ligation-dependent probe amplification did not show variants in the CTNS gene. Pending further genetic analysis, treatment with cysteamine bitartrate was continued. Cysteamine bitartrate treatment completely normalized cystine levels in granulocytes $(0.03 \mathrm{nmol} / \mathrm{mg})$, which was considered very unusual for a patient with nephropathic cystinosis. Further, ophthalmologic examination did not show corneal deposition of cystine crystals. Cysteamine bitartrate treatment was therefore withheld, after which cystine levels in granulocytes increased slightly to levels below those reported in heterozygous carriers of CTNS 
variants $(0.22 \mathrm{nmol} / \mathrm{mg})$. Diagnostic renal gene panel (a panel of renal genes from whole exome sequencing data) analysis was performed, which reiterated the negative result in CTNS but demonstrated two heterozygous pathogenic variants in ATP6V1B1 (NM_001692.3:c.[175$1 G>C] ;[1155 d u p]$, p. [(?)];[(Ile386fs)]). ${ }^{23}$ By analyzing the parents, the variants were shown to be in trans.

With these findings, a definite diagnosis of distal renal tubular acidosis and deafness (OMIM \#267300) was established. Sodium phosphate and alfacalcidol supplementation was stopped, while treatment with potassium citrate was continued. The treatment resolved hypophosphatemia, generalized aminoaciduria, rickets, and improved the height Z-score to -0.65 . However, the patient still presented a mildly increased urinary excretion of $\beta 2$ microglobulin (Table 1), suggesting a mild defect in proximal tubules. This prompted us to further investigate the possible link between ATP6V1B1 gene deficiency and the occurrence of a generalized proximal renal tubular defect.

\section{V-ATPase B1 subunit is expressed along the human distal and proximal segments of the}

nephron. To study the role of the V-ATPase B1 subunit in proximal tubules, we first assessed its expression in healthy human kidney tissue by immunohistochemistry. As shown in Figure $1 \mathrm{~A}$, ATP6V1B1 is expressed in both proximal and distal tubules although with different levels of intensity. High-intensity staining was observed mainly in distal tubules, whereas low-intensity staining was mostly located to proximal tubules. In contrast, no staining was observed in the glomeruli. 


\section{CRISPR-generated ATP6V1B1\% ciPTEC display increased cystine accumulation and autophagy}

activation. To dissect the underlying cellular mechanisms of the lysosomal V-ATPase B1 subunit in proximal tubules, we introduced a pathogenic variant in the ATP6V1B1 gene by CRISPR/Cas9 in proximal tubule cells. After cell sorting and subsequent clonal cell expansion, two clones with biallelic variants (ATP6V1B1 $1^{-1-1}$ and ATP6V1B1 $1^{-/-2}$ ) were selected for subsequent experiments. Both ATP6V1B1-deficient renal proximal tubule cells displayed a significant increase in cystine levels ( 3-fold), indicating the cystinosin transport function is reduced in absence of the lysosomal V-ATPase B1 subunit (Figure 1B). Nevertheless, the cystine levels were not as high as those found in the isogenic CTNS $^{-/}$cells (45-fold increase compared to control) (Figure 1B). Consistent with the patient data, cysteamine treatment completely normalized cystine levels in ATP6V1B1\%- cells, but not in CTNS ${ }^{-/}$cells (Figure 1B). Cystine levels in CTNS ${ }^{-/}$cells treated with cysteamine was still higher (7.5-fold) than that found in control cells (Figure 1B).

When looking at the mRNA levels, we found a small (less than 2-fold) reduction in CTNS mRNA expression in the ATP6V1B1 deficient cells (Supplementary figure S1A). It is not expected that this change in mRNA will directly affect the cystine transport function, especially as the same reduction in mRNA is seen in the proximal tubule cells bearing a heterozygous CTNS mutation $\left(\right.$ CTNS $^{+-}$cells), which does not result in cystine accumulation (Supplementary figure S1A, figure 1B). This indicates that the accumulation of cystine in ATP6V1B1\% cells is not due to a lack in cystinosin protein levels, but rather caused by a reduced efficiency in the cystinosin activity. It is worth mentioning that CTNS $^{-/-}$cells also show a decreased ATP6V1B1 mRNA expression (1.5-fold) compared to control cells (supplementary figure S1B), suggesting there may also be a regulatory link between the expression of these genes. 
The lysosomal V-ATPase is a component of the mTOR complex and is involved in autophagy regulation. ${ }^{12}$ Disruption of the mTORC1 complex and its dissociation from lysosomes is correlated with TFEB nuclear translocation and induction of autophagy, as also seen in cystinosis. ${ }^{17}$ In agreement with reduced mTOR activity, a 3.0-fold increase in TFEB nuclear translocation was observed in both ATP6V1B1 knockout lines compared to control cells, comparable to CTNS $^{-/}$cells (2.3-fold; Figure 2A, 2B). As TFEB is known to downregulate its own expression after activation, we also found that the endogenous TFEB mRNA expression was reduced in all three lines ( 1.5-fold), when compared to control cells (Figure 2C). During autophagy, LC3-II (Microtubuleassociated protein $1 \mathrm{~A} / 1 \mathrm{~B}$-light chain 3 ) is recruited to autophagosomes and its accumulation is correlated with abnormal induction of autophagy. ${ }^{24}$ In accordance, we found significant increase in the LC3-II levels in both the CTNS and ATP6V1B1 knockout cells compared to control cells (Figure 2D). We also assessed the effect of the ATP6V1B1 gene defect on endocytosis and lysosomal-cargo degradation in the knockout lines using BSA and DQ-BSA uptake, respectively. ATP6V1B1 knockout lines maintained endocytosis and displayed increased endocytic cargo processing function (Figure 2E, 2F). CTNS $\%$ cells, similar to ATP6V1B1\% cells, maintained endocytosis functionality but, in contrast displayed a reduced ability ( 2.5 -fold) to degrade endocytic cargo compared to control cells (Figure 2E, 2F).

Together, our data indicate that in proximal tubule cells, ATP6V1B1 plays a role in autophagy activation and lysosomal cystine transport, without having an effect on the lysosomal vesicular trafficking and degradation.

Metabolic and proteomic profiling link the lysosomal V-ATPase B1 subunit to nephropathic cystinosis. To further investigate the role of the B1 subunit of the lysosomal V-ATPase in proximal 
tubules and its contribution to cystinosis pathophysiology, we performed semi-targeted metabolomics and untargeted proteomics in $\mathrm{ATP}_{\mathrm{N}} 1 \mathrm{B1} 1^{\%}, \mathrm{CTNS}^{-}$and control cells (Figure 3, 4). Principal component analysis (PCA) of the 100 measured metabolites and over 3,474 identified proteins (Figure 3A, 4A) demonstrated that both $\mathrm{CTNS}^{--}$and $\mathrm{ATP} 6 \mathrm{~V} 1 \mathrm{~B} 1^{-/}$cells share quite similar metabolic and proteomic profiles and are different from the control cells. This was further visualized by unsupervised hierarchical clustering in which ATP6V1B1-- cells clustered with CTNS /- cells but not with control cells (Figure 3B). Moreover, pathway enrichment analysis of the metabolites revealed multiple numbers of similarly affected pathways in the two diseased cells, including the arginine and proline metabolism, the ß-alanine metabolism, and the alanine, aspartate and glutamate metabolism (Figure 3C, 3D), providing additional evidence that defects in both genes result in similar metabolic disruptions in proximal tubule cells.

To unravel the role of the lysosomal V-ATPase B1 subunit in proximal tubules we first evaluated metabolite and protein expression differences between ATP6V1B1\% and control cells (Figure 3E, 4B), and the differentially expressed metabolites and proteins were then compared with those in $\mathrm{CTNS}^{-}$- cells. About $50 \%$ of the quantified metabolites (especially amino acids that are involved in acid regulation) ${ }^{25,26}$ were altered as a result of ATP6V1B1 loss in proximal tubule cells (Figure 3E). Cross-checking individual metabolites that were similarly affected in both ATP6V1B1\% and CTNS $^{-/}$cells, revealed that CTNS $^{-/-}$cells also present a fairly similar metabolite alteration as those found in ATP6V1B1\% cells (Figure 3F, 3G). Proteomic profiling, on the other hand, revealed a total of 562 proteins that were differentially expressed in ATP6V1B1\% and $\mathrm{CTNS}^{-1-}$ cells compared to controls (Figure 4C). Hierarchical clustering of these proteins resulted in five main protein clusters. Clusters A and E (in orange) represent proteins that were similarly affected in both 
ATP6V1B1\% and $\mathrm{CTNS}^{-\%}$ cells compared to control cells, clusters B and D (in blue) show proteins affected differently in the ATP6V1B1\% as compared to the $\mathrm{CTNS}^{\%}$ and control cells, and cluster C (in black) indicates proteins affected differently in the CTNS ${ }^{-/}$as compared to ATP6V1B1\% and control cells. The differentially abundant proteins were then subjected to gene ontology classification via the Panther Classification System database ${ }^{27}$ to highlight their biological and molecular functions, and cellular component in the cells (Figure 4D). The analysis showed an overall reduction in proteins involved in catalytic activity, oxidoreductase activity, cell-cell adhesion, organelle organization, and focal adhesion in ATP6V1B1\% and CTNS $\%$ cells compared to controls. Key proteins involved in lysosomal cargo degradation, namely lysosomal acid phosphatase (ACP2), Cathepsin B (CTSB), and mannose 6-phosphate receptors (M6PRs; IGFR2, receptors responsible for the delivery of newly synthesised lysosomal enzymes from Golgi to the lysosome), that were shown to be dysregulated in $\mathrm{CTNS}^{-/-}$cells, ${ }^{17}$ were not affected in ATP6V1B1I- cells (Figure 4E-Cluster-C). However, lysosome-associated membrane glycoprotein-1 (LAMP1), and Ragulator complex protein LAMTOR1 were found significantly downregulated in both ATP6V1B1\% and CTNS $\%$ cells compared to controls (Figure 4E-Cluster-E). ATP6V1B1\% cells also showed a decreased expression of several autophagy-regulatory proteins, Rab proteins (Figure 4E-Cluster-B, D), confirming that the loss of ATP6V1B1 in proximal tubule cells results in abnormal autophagy activation, but without influencing the lysosomal cargo degradation. ATP6V1B1\%-and CTNS $^{--}$cells also presented decreased expression of tight junction protein, Zonula occludin-1 (TJP1; ZO-1) and gap junction alpha-1 protein (GJA1), and increased expression of lectin and $\beta$ galactoside-binding protein family 21, galectin-3 (LGALS3; Figure 4E-Cluster-A), markers of kidney 
bioRxiv preprint doi: https://doi.org/10.1101/2020.07.24.219808; this version posted July 25, 2020. The copyright holder for this preprint (which was not certified by peer review) is the author/funder. All rights reserved. No reuse allowed without permission.

disease progression. Altogether, our findings suggest the V-ATPase B1 plays an important role in proximal tubular epithelial cells contributing to renal disease. 


\section{Discussion}

In this work, we revealed a previously unrecognized role of the lysosomal V-ATPase B1 subunit in renal proximal tubular epithelial cells and showed its loss could have similar effects on the cells as CTNS loss. In line with the clinical findings, the ATP6V1B1 gene defect in proximal tubule cells hampered cystinosin regulation and resulted in cystine accumulation, which was completely normalized by cysteamine. The loss of ATP6V1B1 also entailed drastic cellular changes with a marked induction of autophagy and metabolic acidosis in proximal tubule cells, without influencing the lysosomal vesicular trafficking.

V-ATPases are large multisubunit complexes that utilize the energy derived from the hydrolysis of cytosolic ATP to transport protons across biological membranes and maintain the acidic $\mathrm{pH}$ of endocytic and secretory organelles. ${ }^{28,29}$ They are ubiquitously distributed on intracellular tubulovesicular membranes, and also at the plasma membrane in specialized cell types. The B1 subunit of the V-ATPase has been found expressed only in intercalated cells of the kidney, ${ }^{8-10,30}$ inner ear, ${ }^{7}$ ocular ciliary epithelium, ${ }^{31}$ male reproductive tract, $^{32}$ and placenta. $^{33}$ The functional importance of the ATP6V1B1 gene in kidney and auditory physiology is evidenced by the fact that mice and humans with variants in this gene develop the autosomal recessive dRTA with deafness. ${ }^{6,7,34}$ However, the fact that our patient with ATP6V1B1 variants also developed symptoms of cystinosis and renal Fanconi syndrome, demonstrated by increased granulocyte cystine levels, generalized aminoaciduria, and urinary excretion of $\beta 2$-microglobulin, prompted us to investigate the possible link between ATP6V1B1 gene deficiency and the occurrence of a generalized renal proximal tubular defect. 
We demonstrated that ATP6V1B1 is expressed in proximal tubules in human kidney tissue, though to a lesser extent than in distal tubules. In addition, when we specifically knocked out the ATP6V1B1 gene in human renal proximal tubule cells, we found increased cystine levels with autophagy activation. Cystinosin is a $\mathrm{H}^{+}$/cystine symporter that requires lysosomal $\mathrm{H}^{+}$influx mediated by the lysosomal V-ATPase to transport cystine to the cytoplasm. ${ }^{13}$ The loss of ATP6V1B1 likely disrupted the chemiosmotic coupling between the lysosomal V-ATPase B1 subunit and cystinosin and resulted in intralysosomal accumulation of cystine in proximal tubule cells (Figure 5). Using an omics-based strategy, we also provided evidence that defects in both genes may cause proximal renal tubular acidosis. The proximal tubule is the primary site for active solute reabsorption and secretion, and plays a central role in acid-base balance. ${ }^{35,36}$ During metabolic acidosis, the proximal tubule alters its metabolism and transport properties, leading to increased glutamine levels and renal ammoniagenesis to excrete more acid into urine. ${ }^{25,37,38}$ In accordance, we observed an accumulation of glutamine in the both diseased cells. This could be due to either increased uptake or decreased catabolism of glutamine as a result of decreased expression of glutamines enzyme (GLS) in ATP6V1B1 and CTNS deficient cells.

Furthermore, $A T P 6 V 1 B 1^{-}$and $\mathrm{CTNS}^{-}$proximal tubule cells showed decreased levels of lactate and increased levels of pyruvate and tricarboxylic acid (TCA) cycle intermediates, namely cisaconitate, malate and citrate. This is in agreement with the findings of LaMonte et al., where they demonstrated that metabolic acidosis induces aerobic glycolysis, redirecting glucose away from lactate production and towards the TCA cycle in human cancer cells. ${ }^{26}$ Proteomic analysis, on the other hand, revealed that the loss of either ATP6V1B1 or cystinosin is accompanied with decreased expression of tight junction protein (ZO-1 and GJA1), indicating proximal tubular 
epithelial dysfunction and disrupted tight junction integrity. ${ }^{15,39,40}$ ATP6V1B1\% and CTNS ${ }^{-/}$cells also presented increased expression of galectin-3, a protein demonstrated to be markedly upregulated in acute tubular injury ${ }^{41}$ and in progressive renal fibrosis. ${ }^{42}$ Lobry et al., demonstrated that cystinosin loss-of-function results in galectin-3 overexpression in cystinotic mice kidneys, inducing macrophage infiltration and kidney disease progression. ${ }^{43}$ In light of our present data taken together with the clinical findings, we indicate that the V-ATPase B1 subunit plays an important role in acid-base homeostasis and is involved in the occurrence of a generalized proximal renal tubular defect that could functionally overlap with the one seen in cystinosis.

Nephropathic cystinosis is the most common genetic cause of renal Fanconi syndrome in children. Variants in CTNS lead to lysosomal accumulation of cystine, reduced mTOR activation, delayed protein degradation and increased oxidative stress in proximal tubule cells. ${ }^{15,17,44-51}$ It is known that cystinosin can directly interact with V-ATPase-Ragulator-Rag Complex on the Iysosomal membrane, regulating mTOR-mediated autophagy..$^{12}$ On the other hand, V-ATPase was also identified as a potential amino acid sensing protein that can recruit and activate mTORC1. ${ }^{52}$ Here, we demonstrated that the defect or the decreased ATPV1B1 gene expression is corelated with the increased TFEB nuclear translocation and subsequent autophagy activation (Figure 5). Hence, the fact that $\mathrm{CTNS}^{-/}$cells have increased autophagy activation could be a direct result of the decreased activity of ATP6V1B1, disabling mTOR recruitment to the lysosomes and subsequent deactivation of mTOR signaling, in line with with previous reports demonstrating reduced mTOR activity in in vitro and in vivo models of cystinosis. ${ }^{12,15,17,53,54}$ This was further evidenced when Ragulator complex protein LAMTOR1 and LAMP1 were downregulated in both 
ATP6V1B1\% and CTNS $\%$ cells. LAMTOR1 as a part of V-ATPase-Ragulator-Rag Complex is required for lysosomal recruitment of $\mathrm{mTORC1}$ and consequent activation. Depletion in LAMTOR1 prevents mTOR shuttling to lysosomal surface, resulting in autophagy activation. ${ }^{55,56}$

Taken together, our study identified that ATP6V1B1 is a central player in proximal tubule cells, regulating cystine transport and autophagy, and its absence can lead to proximal tubule dysfunction. 


\section{Author's Contribution}

A.J., M.J.J., and R.M. designed the study; A.M.vE., and M.R.L., performed human study and provided the patient's clinical data; A.J., C.AGH.vG., E.A.Z., F.A.V., R.B., E.Z., and J.E.E. performed experiments; M.A, and C.R.B. provided input on experimental design, manuscript content and data representation; A.J., M.J.J., and R.M interpreted the data and wrote the paper with all coauthors' assistance; M.J.J. and R.M. provided supervision.

\section{Acknowledgements}

This work was financially supported by a grant from the Dutch Kidney Foundation (grant nr.150KG19 and KSTP12-010) and the stofwisselkracht (Druggable Targets In Lysosomal VATPase Dysfunction).

\section{Disclosure:}

The authors declare no conflict of interest.

\section{Supplementary table of contents:}

Supplementary figure 1: The lysosomal V-ATPase B1 interacts with cystinosin. 


\section{References}

1. Town, M, Jean, G, Cherqui, S, Attard, M, Forestier, L, Whitmore, SA, Callen, DF, Gribouval, O, Broyer, $\mathrm{M}$, Bates, GP, van't Hoff, W, Antignac, C: A novel gene encoding an integral membrane protein is mutated in nephropathic cystinosis. Nature genetics, 18: 319-324, 1998.

2. Cherqui, S, Courtoy, PJ: The renal Fanconi syndrome in cystinosis: pathogenic insights and therapeutic perspectives. Nature reviews Nephrology, 13: 115-131, 2017.

3. Foreman, JW: Fanconi Syndrome. Pediatric clinics of North America, 66: 159-167, 2019.

4. Kleta, R, Gahl, WA: Pharmacological treatment of nephropathic cystinosis with cysteamine. Expert opinion on pharmacotherapy, 5: 2255-2262, 2004.

5. Wilmer, MJ, Emma, F, Levtchenko, EN: The pathogenesis of cystinosis: mechanisms beyond cystine accumulation. American journal of physiology Renal physiology, 299: F905-916, 2010.

6. Fry, AC, Karet, FE: Inherited renal acidoses. Physiology (Bethesda, Md), 22: 202-211, 2007.

7. Karet, FE, Finberg, KE, Nelson, RD, Nayir, A, Mocan, H, Sanjad, SA, Rodriguez-Soriano, J, Santos, F, Cremers, CW, Di Pietro, A, Hoffbrand, BI, Winiarski, J, Bakkaloglu, A, Ozen, S, Dusunsel, R, Goodyer, P, Hulton, SA, Wu, DK, Skvorak, AB, Morton, CC, Cunningham, MJ, Jha, V, Lifton, RP: Mutations in the gene encoding B1 subunit of H+-ATPase cause renal tubular acidosis with sensorineural deafness. Nature genetics, 21: 84-90, 1999.

8. Frische, S, Chambrey, R, Trepiccione, F, Zamani, R, Marcussen, N, Alexander, RT, Skjodt, K, Svenningsen, $\mathrm{P}$, Dimke, $\mathrm{H}$ : $\mathrm{H}(+)$-ATPase B1 subunit localizes to thick ascending limb and distal convoluted tubule of rodent and human kidney. American journal of physiology Renal physiology, 315: F429-f444, 2018.

9. Miller, RL, Lucero, OM, Riemondy, KA, Baumgartner, BK, Brown, D, Breton, S, Nelson, RD: The VATPase B1-subunit promoter drives expression of Cre recombinase in intercalated cells of the kidney. Kidney international, 75: 435-439, 2009.

10. Miller, RL, Zhang, P, Smith, M, Beaulieu, V, Paunescu, TG, Brown, D, Breton, S, Nelson, RD: V-ATPase B1-subunit promoter drives expression of EGFP in intercalated cells of kidney, clear cells of epididymis and airway cells of lung in transgenic mice. American journal of physiology Cell physiology, 288: C1134-1144, 2005.

11. Tasic, V, Korneti, P, Gucev, Z, Hoppe, B, Blau, N, Cheong, HI: Atypical presentation of distal renal tubular acidosis in two siblings. Pediatric nephrology (Berlin, Germany), 23: 1177-1181, 2008.

12. Andrzejewska, Z, Nevo, N, Thomas, L, Chhuon, C, Bailleux, A, Chauvet, V, Courtoy, PJ, Chol, M, Guerrera, IC, Antignac, C: Cystinosin is a Component of the Vacuolar H+-ATPase-Ragulator-Rag Complex Controlling Mammalian Target of Rapamycin Complex 1 Signaling. Journal of the American Society of Nephrology : JASN, 27: 1678-1688, 2016.

13. Kalatzis, V, Cherqui, S, Antignac, C, Gasnier, B: Cystinosin, the protein defective in cystinosis, is a $\mathrm{H}(+)$-driven lysosomal cystine transporter. The EMBO journal, 20: 5940-5949, 2001.

14. Sansanwal, P, Sarwal, MM: p62/SQSTM1 prominently accumulates in renal proximal tubules in nephropathic cystinosis. Pediatric nephrology (Berlin, Germany), 27: 2137-2144, 2012.

15. Festa, BP, Chen, Z, Berquez, M, Debaix, H, Tokonami, N, Prange, JA, Hoek, GV, Alessio, C, Raimondi, A, Nevo, N, Giles, RH, Devuyst, O, Luciani, A: Impaired autophagy bridges lysosomal storage disease and epithelial dysfunction in the kidney. Nature communications, 9: 161, 2018.

16. Sardiello, M, Palmieri, M, di Ronza, A, Medina, DL, Valenza, M, Gennarino, VA, Di Malta, C, Donaudy, F, Embrione, V, Polishchuk, RS, Banfi, S, Parenti, G, Cattaneo, E, Ballabio, A: A gene network regulating lysosomal biogenesis and function. Science (New York, NY), 325: 473-477, 2009.

17. Jamalpoor, A, van Gelder, CA, Yousef Yengej, FA, Zaal, EA, Berlingerio, SP, Veys, KR, Casellas, CP, Voskuil, K, Essa, K, Ammerlaan, CM, Rega, LR, van der Welle, R, Lilien, MR, Rookmaaker, MB, Clevers, H, Klumperman, J, Levtchenko, E, Berkers, CR, Verhaar, MC, Altelaar, M, Masereeuw, R, 
Janssen, MJ: Cysteamine-bicalutamide combination treatment restores alpha-ketoglutarate and corrects proximal tubule phenotype in cystinosis. bioRxiv: 2020.2002.2010.941799, 2020.

18. Rega, LR, Polishchuk, E, Montefusco, S, Napolitano, G, Tozzi, G, Zhang, J, Bellomo, F, Taranta, A, Pastore, A, Polishchuk, R, Piemonte, F, Medina, DL, Catz, SD, Ballabio, A, Emma, F: Activation of the transcription factor EB rescues lysosomal abnormalities in cystinotic kidney cells. Kidney international, 89: 862-873, 2016.

19. van Diest, PJ: No consent should be needed for using leftover body material for scientific purposes. For. BMJ (Clinical research ed), 325: 648-651, 2002.

20. Wilmer, MJ, Saleem, MA, Masereeuw, R, Ni, L, van der Velden, TJ, Russel, FG, Mathieson, PW, Monnens, LA, van den Heuvel, LP, Levtchenko, EN: Novel conditionally immortalized human proximal tubule cell line expressing functional influx and efflux transporters. Cell and tissue research, 339: 449-457, 2010.

21. Ran, FA, Hsu, PD, Wright, J, Agarwala, V, Scott, DA, Zhang, F: Genome engineering using the CRISPRCas9 system. Nature protocols, 8: 2281-2308, 2013.

22. Jamalpoor, A, Sparidans, RW, Pou Casellas, C, Rood, JJM, Joshi, M, Masereeuw, R, Janssen, MJ: Quantification of cystine in human renal proximal tubule cells using liquid chromatographytandem mass spectrometry. Biomedical chromatography : BMC: e4238, 2018.

23. Richards, S, Aziz, N, Bale, S, Bick, D, Das, S, Gastier-Foster, J, Grody, WW, Hegde, M, Lyon, E, Spector, $\mathrm{E}$, Voelkerding, K, Rehm, HL: Standards and guidelines for the interpretation of sequence variants: a joint consensus recommendation of the American College of Medical Genetics and Genomics and the Association for Molecular Pathology. Genetics in medicine : official journal of the American College of Medical Genetics, 17: 405-424, 2015.

24. Yoshii, SR, Mizushima, N: Monitoring and Measuring Autophagy. International journal of molecular sciences, 18, 2017.

25. Tannen, RL, Sahai, A: Biochemical pathways and modulators of renal ammoniagenesis. Mineral and electrolyte metabolism, 16: 249-258, 1990.

26. Lamonte, G, Tang, X, Chen, JL, Wu, J, Ding, CK, Keenan, MM, Sangokoya, C, Kung, HN, Ilkayeva, O, Boros, LG, Newgard, CB, Chi, JT: Acidosis induces reprogramming of cellular metabolism to mitigate oxidative stress. Cancer \& metabolism, 1: 23, 2013.

27. Thomas, PD, Kejariwal, A, Campbell, MJ, Mi, H, Diemer, K, Guo, N, Ladunga, I, Ulitsky-Lazareva, B, Muruganujan, A, Rabkin, S, Vandergriff, JA, Doremieux, O: PANTHER: a browsable database of gene products organized by biological function, using curated protein family and subfamily classification. Nucleic acids research, 31: 334-341, 2003.

28. Forgac, M: Vacuolar ATPases: rotary proton pumps in physiology and pathophysiology. Nature reviews Molecular cell biology, 8: 917-929, 2007.

29. Marshansky, V, Futai, M: The V-type H+-ATPase in vesicular trafficking: targeting, regulation and function. Current opinion in cell biology, 20: 415-426, 2008.

30. Nelson, RD, Guo, XL, Masood, K, Brown, D, Kalkbrenner, M, Gluck, S: Selectively amplified expression of an isoform of the vacuolar $\mathrm{H}(+)$-ATPase 56-kilodalton subunit in renal intercalated cells. Proceedings of the National Academy of Sciences of the United States of America, 89: 35413545, 1992.

31. Wax, MB, Saito, I, Tenkova, T, Krupin, T, Becker, B, Nelson, N, Brown, D, Gluck, SL: Vacuolar H+ATPase in ocular ciliary epithelium. Proceedings of the National Academy of Sciences of the United States of America, 94: 6752-6757, 1997.

32. Breton, S, Smith, PJ, Lui, B, Brown, D: Acidification of the male reproductive tract by a proton pumping $(\mathrm{H}+)$-ATPase. Nature medicine, 2: 470-472, 1996. 
33. van Hille, B, Richener, H, Schmid, P, Puettner, I, Green, JR, Bilbe, G: Heterogeneity of vacuolar H(+)ATPase: differential expression of two human subunit B isoforms. The Biochemical journal, 303 ( Pt 1): 191-198, 1994.

34. Finberg, KE, Wagner, CA, Bailey, MA, Paunescu, TG, Breton, S, Brown, D, Giebisch, G, Geibel, JP, Lifton, RP: The B1-subunit of the $\mathrm{H}(+)$ ATPase is required for maximal urinary acidification. Proceedings of the National Academy of Sciences of the United States of America, 102: 1361613621, 2005.

35. Curthoys, NP, Moe, OW: Proximal tubule function and response to acidosis. Clinical journal of the American Society of Nephrology: CJASN, 9: 1627-1638, 2014.

36. Wang, K, Kestenbaum, B: Proximal Tubular Secretory Clearance: A Neglected Partner of Kidney Function. Clinical journal of the American Society of Nephrology : CJASN, 13: 1291-1296, 2018.

37. Taylor, L, Curthoys, NP: Glutamine metabolism: Role in acid-base balance*. Biochemistry and molecular biology education : a bimonthly publication of the International Union of Biochemistry and Molecular Biology, 32: 291-304, 2004.

38. Lotspeich, WD: Metabolic aspects of acid-base change. Science (New York, NY), 155: 1066-1075, 1967.

39. Raggi, C, Terryn, S, Devuyst, O, Luciani, A, Antignac, C, Nevo, N: Dedifferentiation and aberrations of the endolysosomal compartment characterize the early stage of nephropathic cystinosis. Human molecular genetics, 23: 2266-2278, 2013.

40. Lima, WR, Parreira, KS, Devuyst, O, Caplanusi, A, N`Kuli, F, Marien, B, Smissen, PVD, Alves, PMS, Verroust, P, Christensen, EI, Terzi, F, Matter, K, Balda, MS, Pierreux, CE, Courtoy, PJ: ZONAB Promotes Proliferation and Represses Differentiation of Proximal Tubule Epithelial Cells. Journal of the American Society of Nephrology: ASN.2009070698, 2010.

41. Nishiyama, J, Kobayashi, S, Ishida, A, Nakabayashi, I, Tajima, O, Miura, S, Katayama, M, Nogami, H: Up-regulation of galectin-3 in acute renal failure of the rat. The American journal of pathology, 157: 815-823, 2000.

42. Henderson, NC, Mackinnon, AC, Farnworth, SL, Kipari, T, Haslett, C, Iredale, JP, Liu, FT, Hughes, J, Sethi, T: Galectin-3 expression and secretion links macrophages to the promotion of renal fibrosis. The American journal of pathology, 172: 288-298, 2008.

43. Lobry, T, Miller, R, Nevo, N, Rocca, CJ, Zhang, J, Catz, SD, Moore, F, Thomas, L, Pouly, D, Bailleux, A, Guerrera, IC, Gubler, MC, Cheung, WW, Mak, RH, Montier, T, Antignac, C, Cherqui, S: Interaction between galectin-3 and cystinosin uncovers a pathogenic role of inflammation in kidney involvement of cystinosis. Kidney international, 96: 350-362, 2019.

44. Wilmer, MJ, Kluijtmans, LA, van der Velden, TJ, Willems, PH, Scheffer, PG, Masereeuw, R, Monnens, LA, van den Heuvel, LP, Levtchenko, EN: Cysteamine restores glutathione redox status in cultured cystinotic proximal tubular epithelial cells. Biochimica et biophysica acta, 1812: 643651, 2011.

45. Levtchenko, E, de Graaf-Hess, A, Wilmer, M, van den Heuvel, L, Monnens, L, Blom, H: Altered status of glutathione and its metabolites in cystinotic cells. Nephrology, dialysis, transplantation : official publication of the European Dialysis and Transplant Association - European Renal Association, 20: 1828-1832, 2005.

46. Chol, M, Nevo, N, Cherqui, S, Antignac, C, Rustin, P: Glutathione precursors replenish decreased glutathione pool in cystinotic cell lines. Biochemical and biophysical research communications, 324: 231-235, 2004.

47. Rizzo, C, Ribes, A, Pastore, A, Dionisi-Vici, C, Greco, M, Rizzoni, G, Federici, G: Pyroglutamic aciduria and nephropathic cystinosis. Journal of inherited metabolic disease, 22: 224-226, 1999. 
48. Raggi, C, Luciani, A, Nevo, N, Antignac, C, Terryn, S, Devuyst, O: Dedifferentiation and aberrations of the endolysosomal compartment characterize the early stage of nephropathic cystinosis. Human molecular genetics, 23: 2266-2278, 2014.

49. Ivanova, EA, De Leo, MG, Van Den Heuvel, L, Pastore, A, Dijkman, H, De Matteis, MA, Levtchenko, EN: Endo-lysosomal dysfunction in human proximal tubular epithelial cells deficient for lysosomal cystine transporter cystinosin. PloS one, 10: e0120998, 2015.

50. Settembre, C, Fraldi, A, Jahreiss, L, Spampanato, C, Venturi, C, Medina, D, de Pablo, R, Tacchetti, C, Rubinsztein, DC, Ballabio, A: A block of autophagy in lysosomal storage disorders. Human molecular genetics, 17: 119-129, 2008.

51. Platt, FM, Boland, B, van der Spoel, AC: The cell biology of disease: lysosomal storage disorders: the cellular impact of lysosomal dysfunction. The Journal of cell biology, 199: 723-734, 2012.

52. Zoncu, R, Bar-Peled, L, Efeyan, A, Wang, S, Sancak, Y, Sabatini, DM: mTORC1 senses lysosomal amino acids through an inside-out mechanism that requires the vacuolar $\mathrm{H}(+)$-ATPase. Science (New York, NY), 334: 678-683, 2011.

53. Hollywood, JA, Przepiorski, A, D'Souza, RF, Sreebhavan, S, Wolvetang, EJ, Harrison, PT, Davidson, AJ, Holm, TM: Use of Human Induced Pluripotent Stem Cells and Kidney Organoids To Develop a Cysteamine/mTOR Inhibition Combination Therapy for Cystinosis. Journal of the American Society of Nephrology : JASN, 2020.

54. Ivanova, EA, van den Heuvel, LP, Elmonem, MA, De Smedt, H, Missiaen, L, Pastore, A, Mekahli, D, Bultynck, G, Levtchenko, EN: Altered mTOR signalling in nephropathic cystinosis. Journal of inherited metabolic disease, 39: 457-464, 2016.

55. Sancak, Y, Bar-Peled, L, Zoncu, R, Markhard, AL, Nada, S, Sabatini, DM: Ragulator-Rag complex targets mTORC1 to the lysosomal surface and is necessary for its activation by amino acids. Cell, 141: 290-303, 2010.

56. Bar-Peled, L, Schweitzer, LD, Zoncu, R, Sabatini, DM: Ragulator is a GEF for the rag GTPases that signal amino acid levels to mTORC1. Cell, 150: 1196-1208, 2012. 
Table 1. Laboratory results of a 23-month-old girl with pathogenic ATP6V1B1 variants.

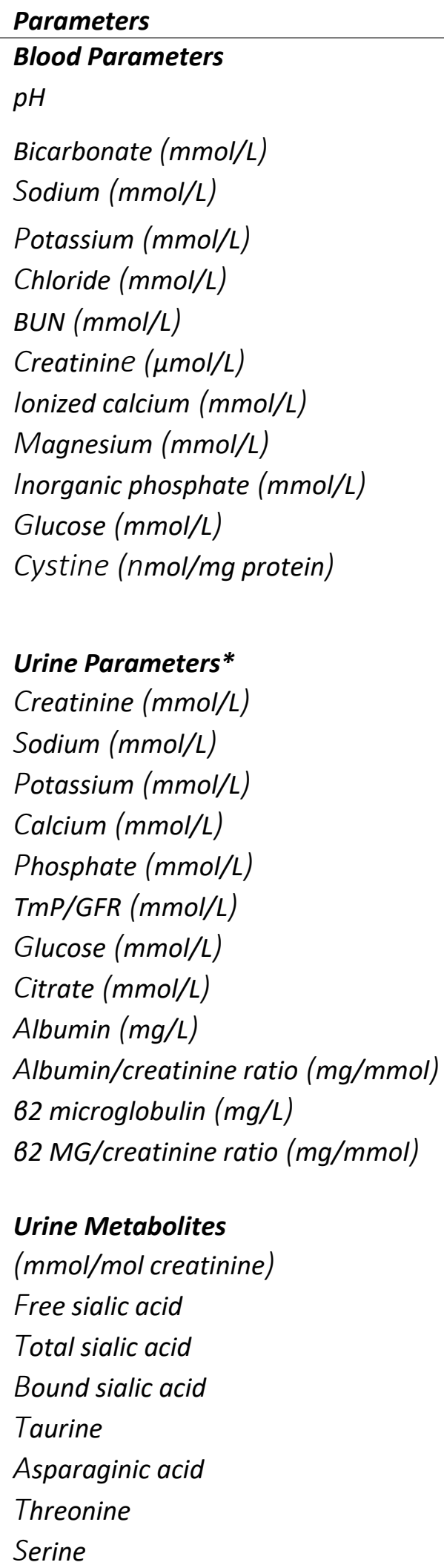

\section{Reference}

$7.35-7.45$

$22-29$

$136-146$

$3.8-5.0$

$99-108$

$3.0-7.5$

$11-34$

$1.15-1.32$

$0.70-1.00$

$1.25-2.10$

$3.6-5.6$

$<0.17$

NA

NA

NA

NA

NA

$1.31-1.73$

NA

$0.6-4.8$

$<30$

$<2.5$

$<0,2$

$<0.04$
7.28

8.9

141

2.9

111

5.8

30

0.96

0.74

4.8

1.02

After-treatment

7.36

22.6

139

3.9

105

6.6

29

1.32

0.98

1.74

4.4

0.22

1.3

49

50

$<1.00$

11.7

1.48

$<1.00$

0.2

8

5.9

94

72.3

$\begin{array}{cc}16-44 & 28 \\ 52-126 & 118 \\ 33-83 & 90 \\ 12-159 & 175 \\ 3-10 & 30 \\ 15-62 & 888 \\ 45-124 & 1045 \\ <32 & 475\end{array}$




\begin{tabular}{l|ccc} 
Glutamic acid & $<11$ & 74 & - \\
Glutamine & $62-165$ & 1895 & - \\
Proline & $<13$ & $<24$ & - \\
Glycine & $110-356$ & 468 & - \\
Alanine & $41-130$ & 157 & - \\
Citrulline & $<7$ & 298 & - \\
Alpha-aminobutyric acid & $<8$ & 49 & - \\
Valine & $7-21$ & 312 & - \\
Cysteine & $5-13$ & 166 & - \\
Isoleucine & $<6$ & 45 & - \\
Leucine & $3-17$ & 124 & - \\
Tyrosine & 1348 & 474 & - \\
phenylalanine & $10-31$ & 180 & - \\
Ornithine & $<8$ & 171 & - \\
Lysine & $16-69$ & 1034 & - \\
Histidine & $87-287$ & 1025 & - \\
Arginine & $<8$ & 66 & - \\
\hline
\end{tabular}

*, There were no results obtained on urine biochemistry prior to the treatment as it was not possible to collect urine; NA, Not applicable; TmP/GFR, Tubular maximal phosphate reabsorption related to glomerular filtration rate. 
Figure Legends:

Figure 1. The V-ATPase B1 subunit is expressed in human proximal tubules and regulates cystinosin. (A) Immunostaining for the V-ATPase B1 subunit (ATP6V1B1) in human kidney tissue with the ATP6V1B1 antibody. Scale bar is $50 \mu \mathrm{m}$. (B) Quantification of cystine levels (nmol/mg protein) by HPLC-MS/MS in wild type (control), two clones of ATP6V1B1\%, $\mathrm{CTNS}^{+/}$, and $\mathrm{CTNS}^{-/}$ cells treated with or without cysteamine $(100 \mu \mathrm{M})$. Data are expressed as the mean \pm SEM of at least three independent experiments performed in triplicate. Statistical analysis was performed using one-way analysis of variance (ANOVA) followed by Dunnett's multiple comparisons test. Where appropriate, unpaired two-tailed Student's t-test were used. P-values $<0.05$ were significant.

Figure 2. The V-ATPase B1 subunit regulates autophagy without having an effect on the lysosomal vesicular trafficking in proximal tubule cells. (A, B) Representative confocal micrographs and quantification of transcription factor EB (TFEB) nuclear translocation in wild type (control), two clones of ATP6V1B1\%, and $\mathrm{CTNS}^{-/}$cells, respectively. Scale bars are $20 \mu \mathrm{m}$. (C) The levels of TFEB mRNA expression in control, two clones of ATP6V1B1\%, and CTNS $\%$ cells. (D) Representative confocal micrographs and quantification of LC3-II accumulation in control, two clones of ATP6V1B1\%, and CTNS $\%$ cells in presence of $25 \mathrm{nM}$ bafilomycin (BafA1) for $4 \mathrm{hrs}$. Scale bars are $20 \mu \mathrm{m}$. (E, F) Representative confocal micrographs and quantification of BSA and DQ-BSA in control, two clones of $A T P 6 V 1 B 1^{\%}$, and $\mathrm{CTNS}^{\%}$ cells, respectively. Scale bars are 20 $\mu \mathrm{m}$. Data are expressed as the mean \pm SEM of at least three independent experiments performed in triplicate. Statistical analysis was performed using one-way analysis of variance (ANOVA) 
followed by Dunnett's multiple comparisons test. Where appropriate, unpaired two-tailed Student's t-test were used. P-values $<0.05$ were significant.

Figure 3. Defects in both ATP6V1B1 and CTNS genes result in similar metabolic disruptions in proximal tubule cells. (A) Principal component analysis (PCA) of wild type (control), ATP6V1B1\%, and CTNS $^{-/}$cells based on the 100 metabolites measured. (B) Heatmap analysis of metabolites distinctively expressed in control, $A T P 6 V 1 B 1^{-}$, and $\mathrm{CTNS}^{-}$cells. Color code: green lower than control $(p<0.05)$, red higher than control $(p<0.05)$. (C, D) Global test pathway enrichment analysis of the intracellular metabolic interactions distinctively affected in ATP6V1B1\% and $\mathrm{CTNS}^{-/}$cells compared to control cells, respectively. Larger circles further from the $y$-axis and orange-red color show higher impact of pathway affected in cells. (E) List of metabolites that were significantly altered in ATP6V1B1\%- compared to control cells. (F, G) List of metabolites that were shared and significantly upregulated and downregulated in both ATP6V1B1\% and $\mathrm{CTNS}^{-/}$cells compared to control cells, respectively. Data are expressed as the mean \pm SEM of one experiment performed in triplicate. Statistical analysis was performed using one-way analysis of variance (ANOVA). Where appropriate, unpaired two-tailed Student's t-test were used. P-values $<0.05$ were significant.

Figure 4. Proteomic profiling bridges the lysosomal V-ATPase B1 subunit to nephropathic cystinosis. (A) Principal component analysis (PCA) of the measured proteins in wild type (control), ATP6V1B1\%, and $\mathrm{CTNS}^{\%}$ cells. (B) Volcano plot illustrates significantly differentially abundant proteins. The $-\log _{10}$ (Benjamini-Hochberg corrected P-value) is plotted against the $\log _{2}$ (fold change: wild type/ ATP6V1B1\%-). The non-axial vertical lines denote \pm 1.5 -fold change while the non-axial horizontal line denotes $\mathrm{P}=0.05$, which is our significance threshold (prior to logarithmic 
transformation). (C) Heatmap analysis of the proteins distinctively expressed in control, ATP6V1B1\%, and $\mathrm{CTNS}^{-}$cells. The row displays protein feature and the column represents the samples. The row Z-score of each feature is plotted in red-green colour scale. Proteins significantly decreased were displayed in green, while metabolites significantly increased were displayed in red. Hierarchical clustering of these proteins resulted in five main protein clusters. Clusters $\mathrm{A}$ and $\mathrm{E}$ (in orange) represent proteins that were similarly affected in both ATP6V1B1\% and CTNS $^{-}$cells compared to control cells, clusters B and D (in blue) show proteins affected differently in the ATP6V1B1\% as compared to the $\mathrm{CTNS}^{\%}$ and control cells, and cluster C (in black) indicates proteins affected differently in the $\mathrm{CTNS}^{-/}$as compared to ATP6V1B1\%- and control cells. (D) Gene ontology analysis of the proteins in cluster-A, E and cluster-B, D of the Heatmap. (E) List of proteins that were significantly altered in ATP6V1B1\%, and $\mathrm{CTNS}^{-/}$cells compared to control cells. VTA1; Vacuolar protein sorting-associated protein VTA1 homolog, NQO1; NAD(P)H dehydrogenase [quinone] 1, CAT; Catalase, LGALS3; Galectin-3, ANXA6; Annexin A6, RAB5C; Rasrelated protein Rab-5C, RAB21; Ras-related protein Rab-21, RAB5A; Ras-related protein Rab-5A, ACTR10; Actin-related protein 10, ACP2; Lysosomal acid phosphatase, CTSB; Cathepsin B, IGF2R; Mannose-6-phosphate receptors, GSTK1; Glutathione S-transferase kappa-1, GSTM3; Glutathione S-transferase Mu-3, LAMP1; Lysosome-associated membrane glycoprotein 1, LAMTOR1; Ragulator complex protein LAMTOR1, GLS; Glutaminase kidney isoform, TJP1 (ZO-1); Tight junction protein-1, GJA1; Gap junction alpha-1 protein, CRYZ; Quinone oxidoreductase, MDH2; Malate dehydrogenase, IDH2; Isocitrate dehydrogenase. Data are expressed as the mean \pm SEM of one experiment performed in triplicate. Statistical analysis was performed using one- 
way analysis of variance (ANOVA). Where appropriate, unpaired two-tailed Student's t-test were used. P-values $<0.05$ were significant.

Figure 5. The lysosomal V-ATPase B1 subunit is the central interplay between cystinosin and mTOR-signaling, regulating cystine transport and autophagy in proximal tubule cells. ATP; adenosine triphosphate, ADP; adenosine diphosphate, GTP; Guanosine triphosphate, GDP; Guanosine diphosphate, mTOR; mammalian target of rapamycin complex, LC3-II; Microtubuleassociated protein 1A/1B-light chain 3, TFEB; transcription factor EB. 
Supplementary figure S1. The lysosomal V-ATPase B1 interacts with cystinosin. (A) CTNS mRNA expression in two clones of ATP6V1B1 ${ }^{\%}$ and $\mathrm{CTNS}^{+/-}$cells was measured using real-time quantitative polymerase chain reaction, with ribosomal protein S13 (RPS-13) as a reference gene, normalized to wild type (control) cells. (B) The levels of ATP6V1B1 mRNA expression in CTNS ${ }^{-/}$ and control cells. Data are expressed as the mean \pm SEM of at least three independent experiments. Statistical analysis was performed using one-way analysis of variance (ANOVA) followed by Dunnett's multiple comparisons test. P-values $<0.05$ were significant. 


\section{Figure 1}

bioRxiv preprint doi: https://doi.org/10.1101/2020.07.24.219808; this version posted July 25, 2020. The copyright holder for this preprint (which

A was not certified by peer review) is the author/funder. All rights reserved. No reuse allowed without permission.
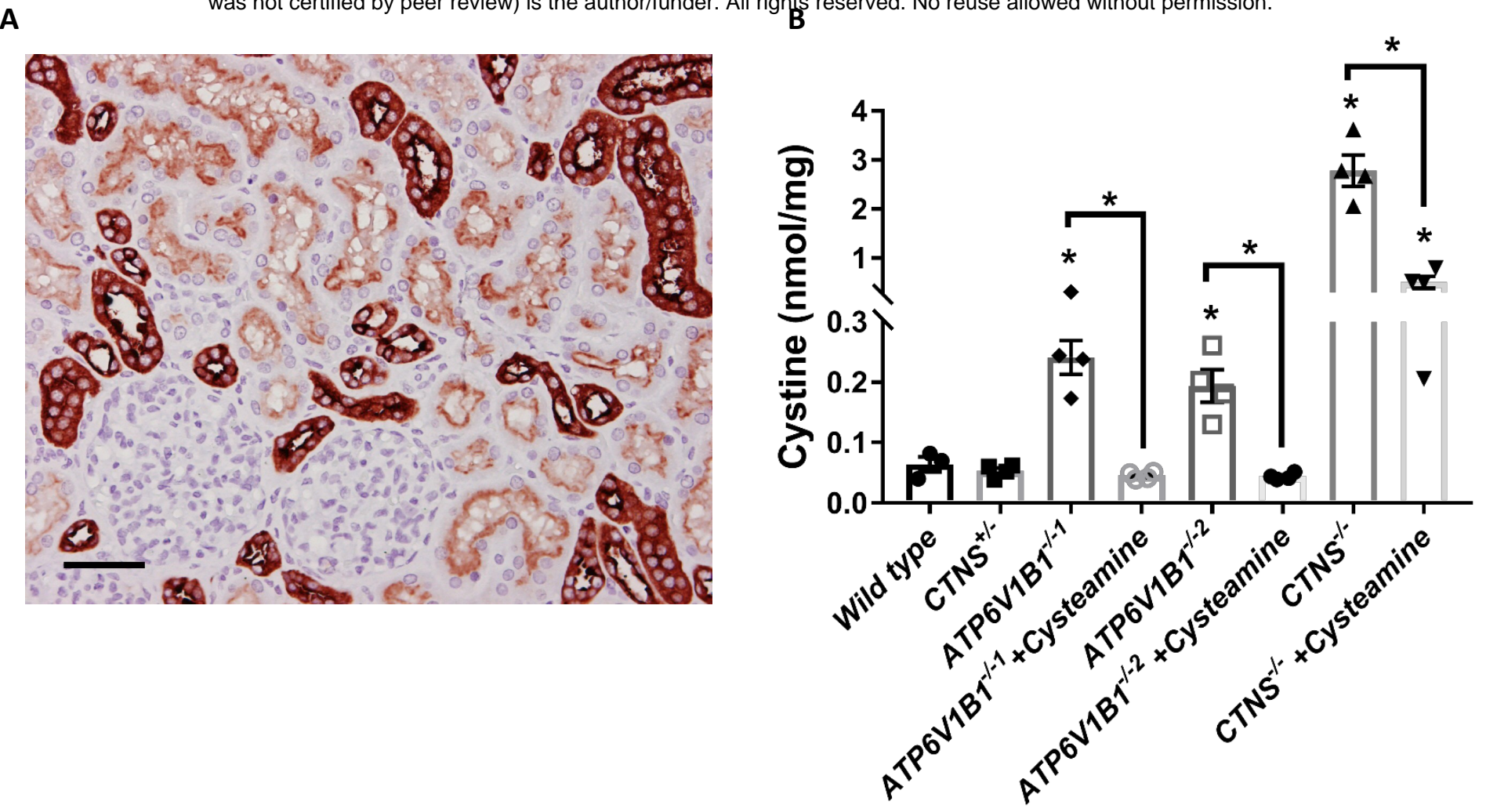
Figure 2

bioRxiv preprint doi: https://doi.org/10.1101/2020.07.24.219808; this version posted July 25, 2020. The copyright holder for this preprint (which was not certified by peer review) is the author/funder. All rights reserved. No reuse allowed without permission.

A

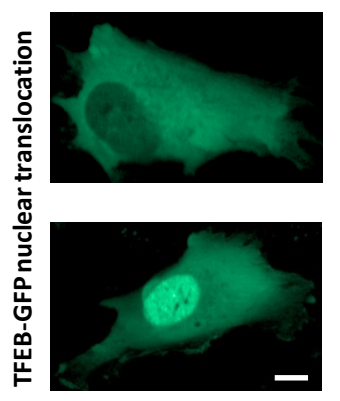

B
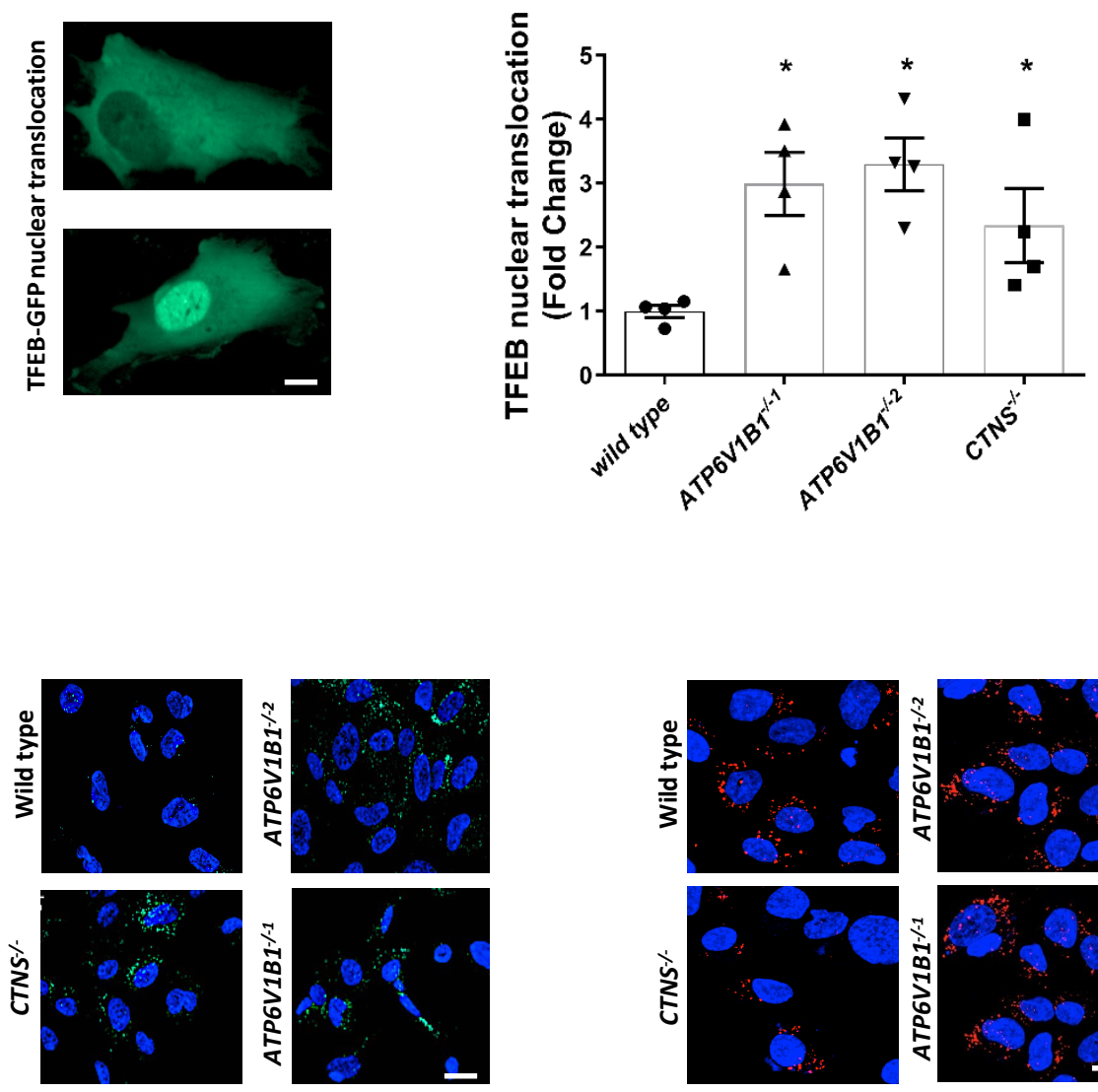

D
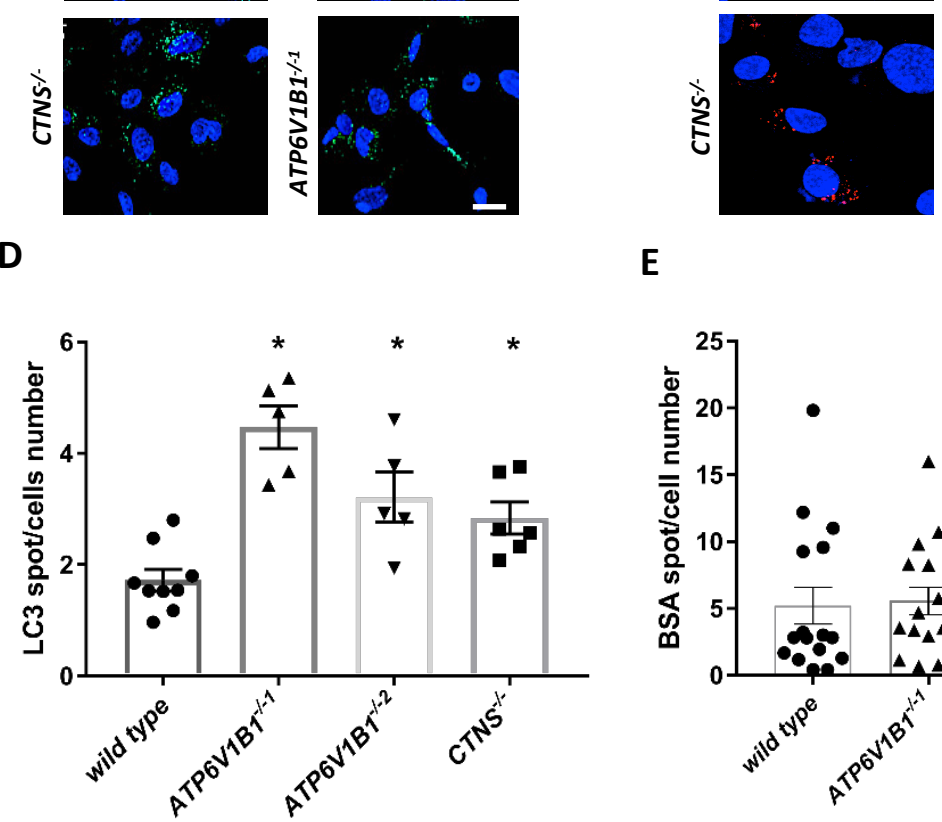

$\mathbf{E}$
C
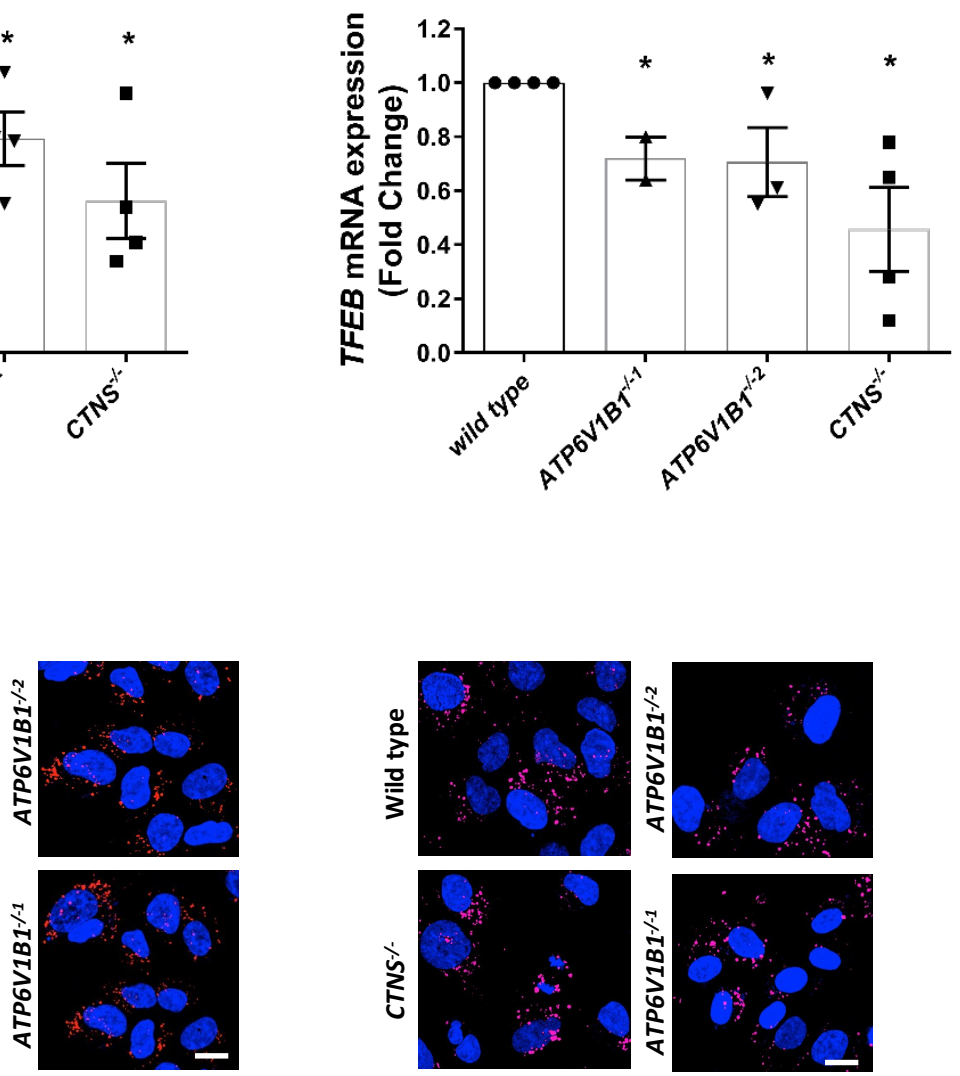

$\mathbf{F}$
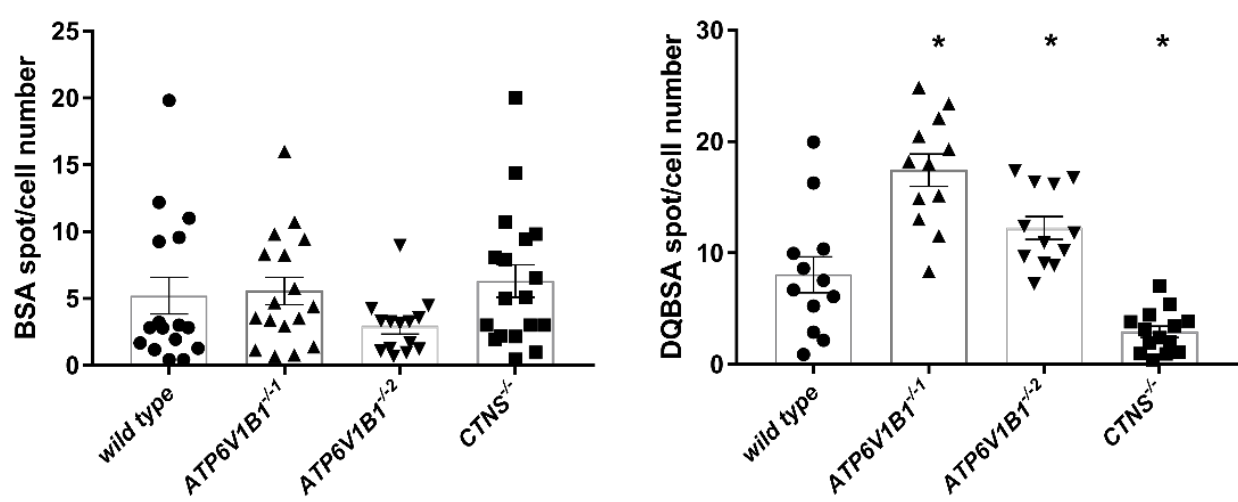
Figure. 3

A

bioRxiv preprint doi: https://doi.org/10.1101/2020.07.24.219808; this version posted July 25, 2020. The copyright holder for this preprint (which

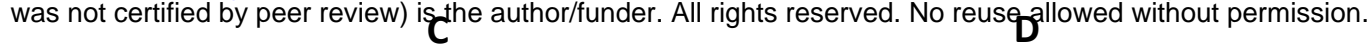

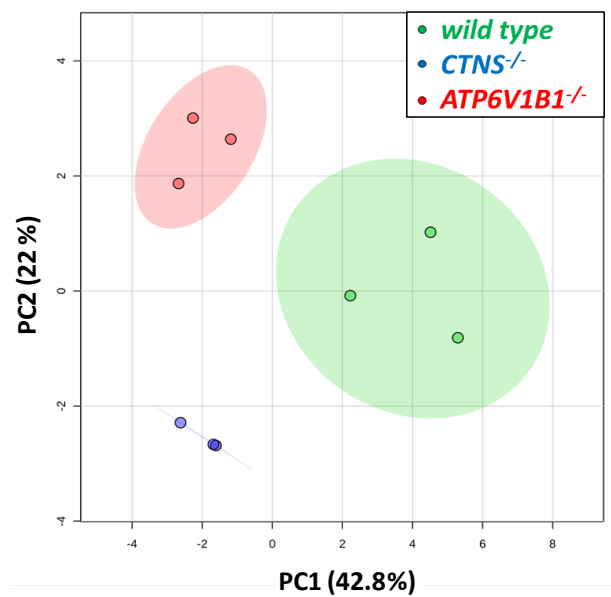

B

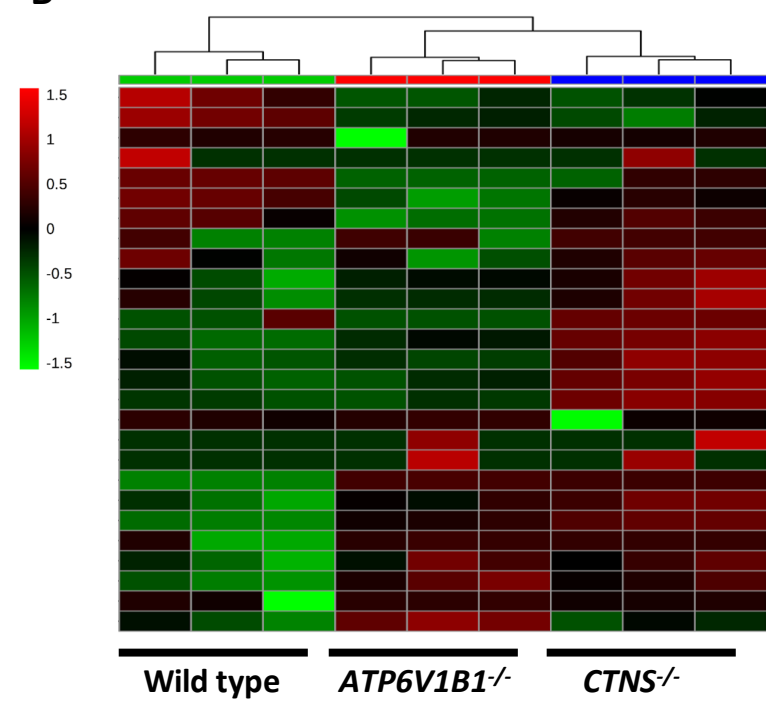

F

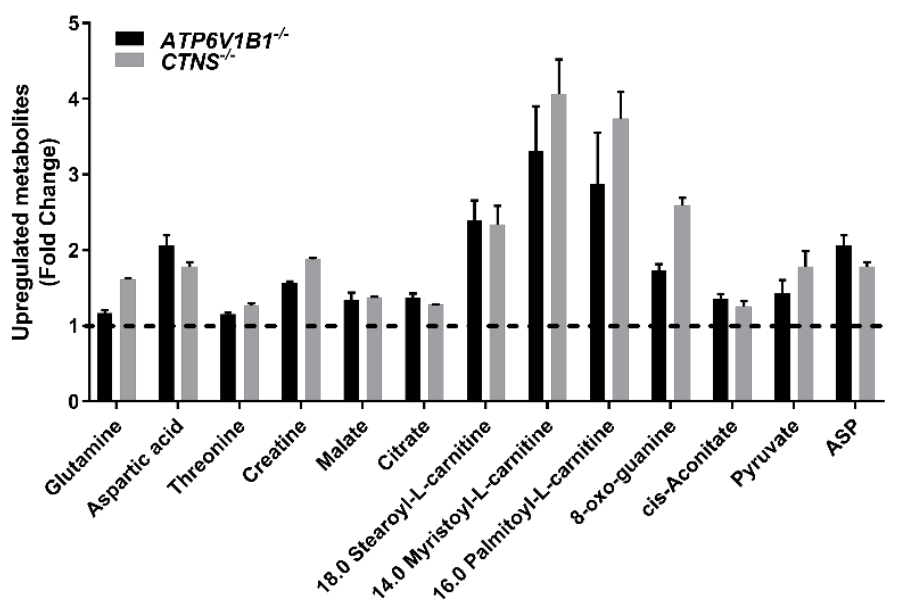

E

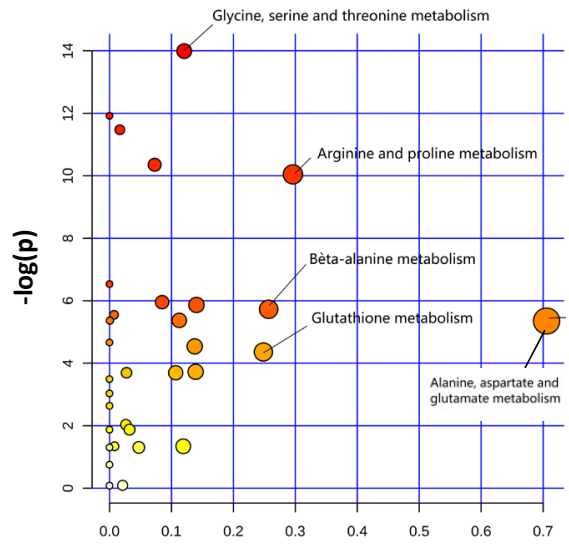

Pathway Impact (Wild type vs ATP6V1B1\%)

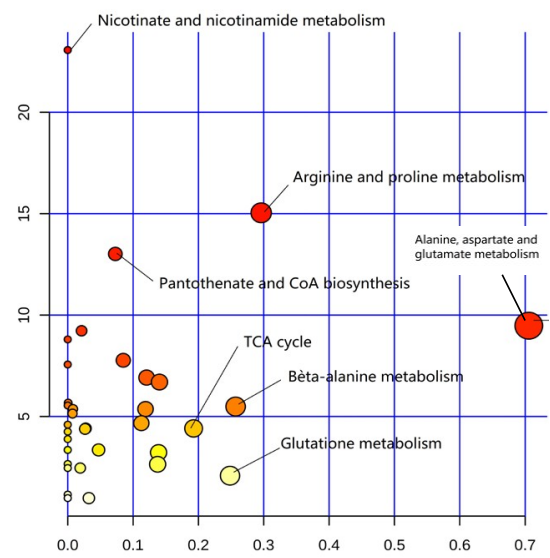

Pathway Impact (Wild type vs CTNS $^{-/}$)

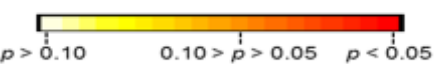

ATP6V1B1/-- VS Wild type

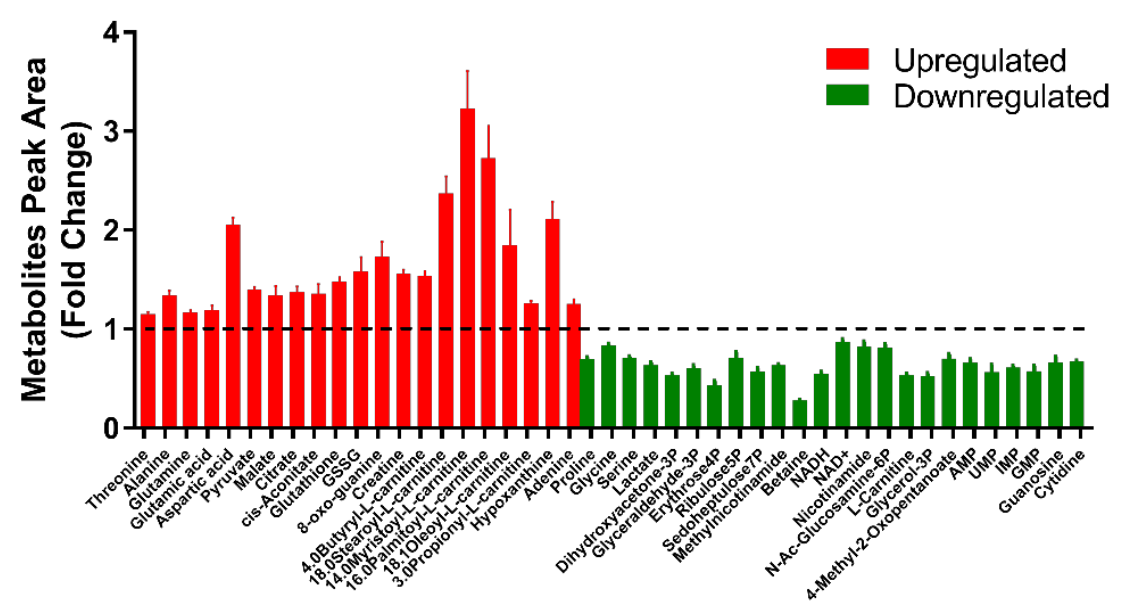

G

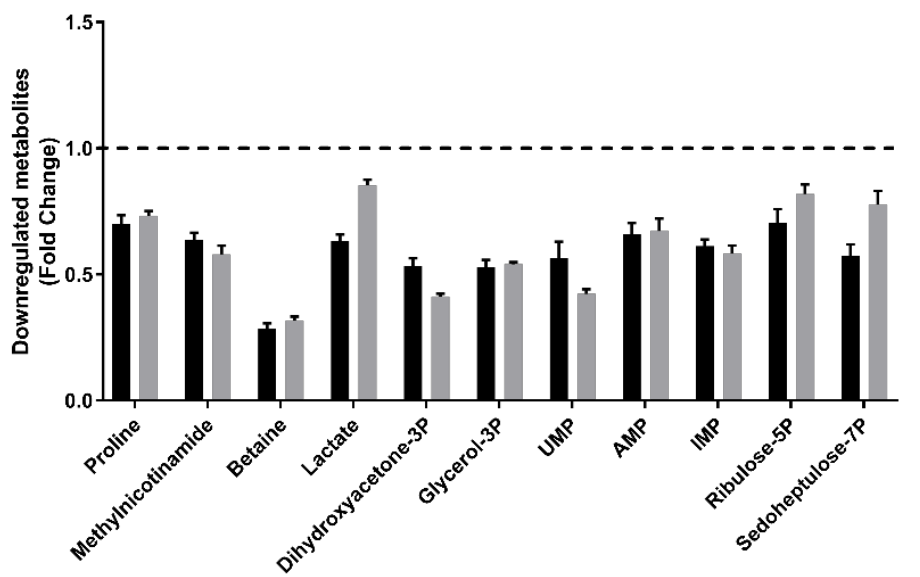


Figure. 4

bioRxiv preprint doi: https://doi.org/10.1101/2020.07.24.219808; this version posted July 25, 2020. The copyright holder for this preprint (which was not certified by peer review) is the author/funder. All rights reserved. No reuse allowed without permission.

A

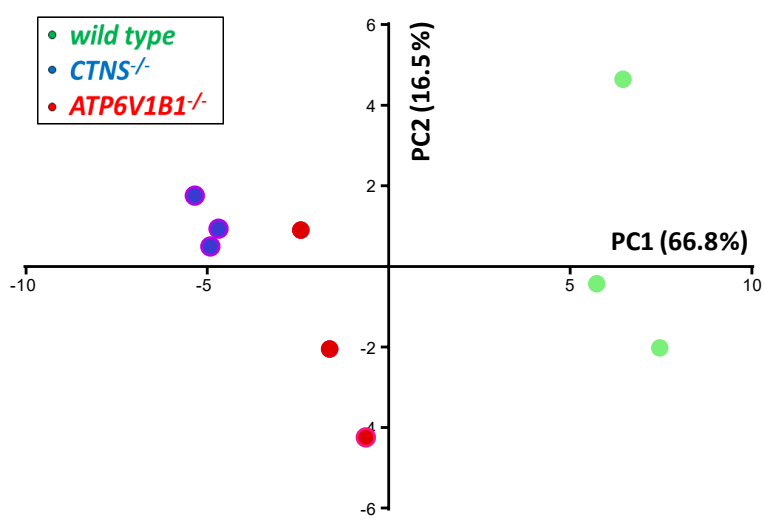

C

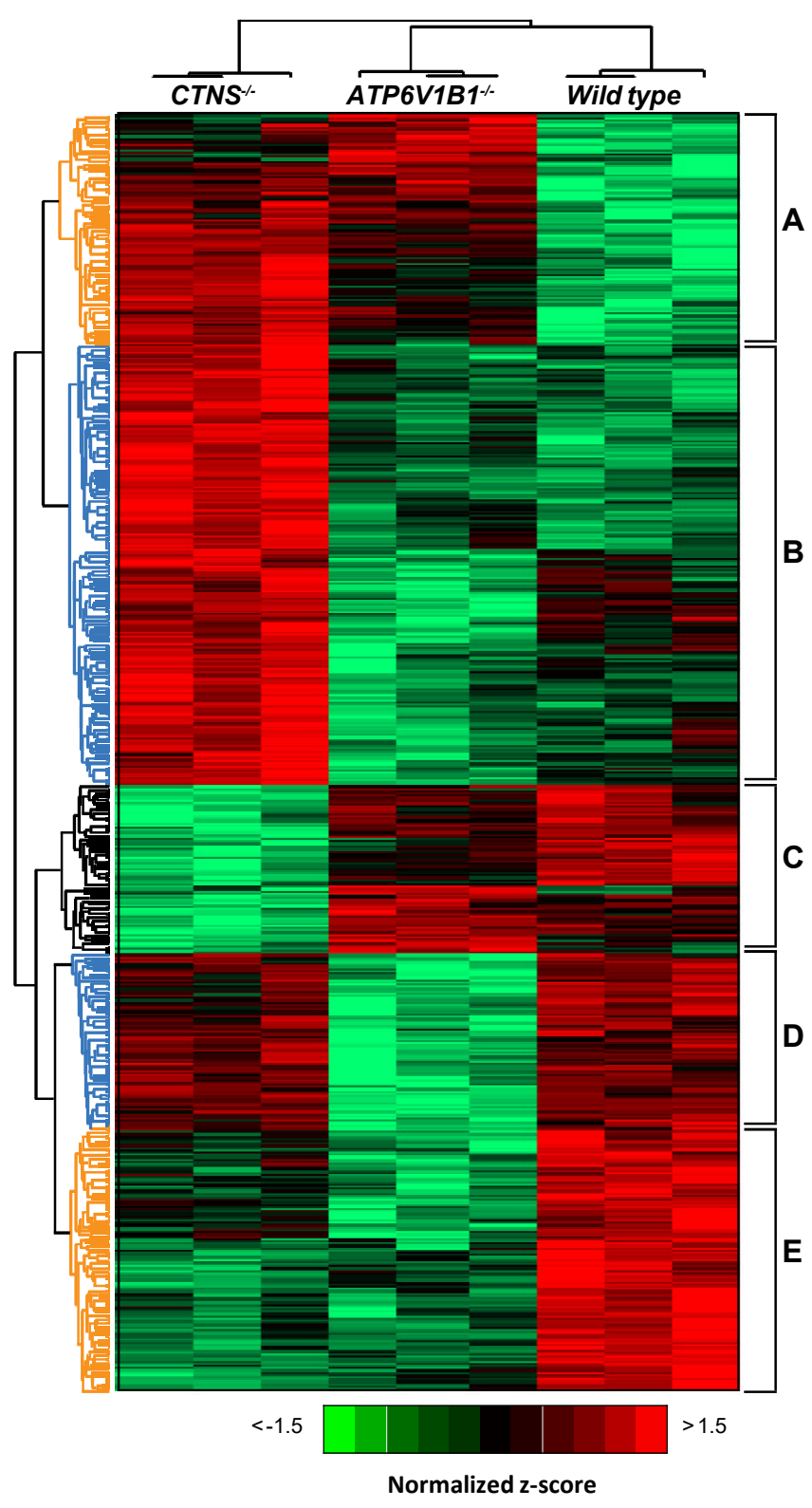

B

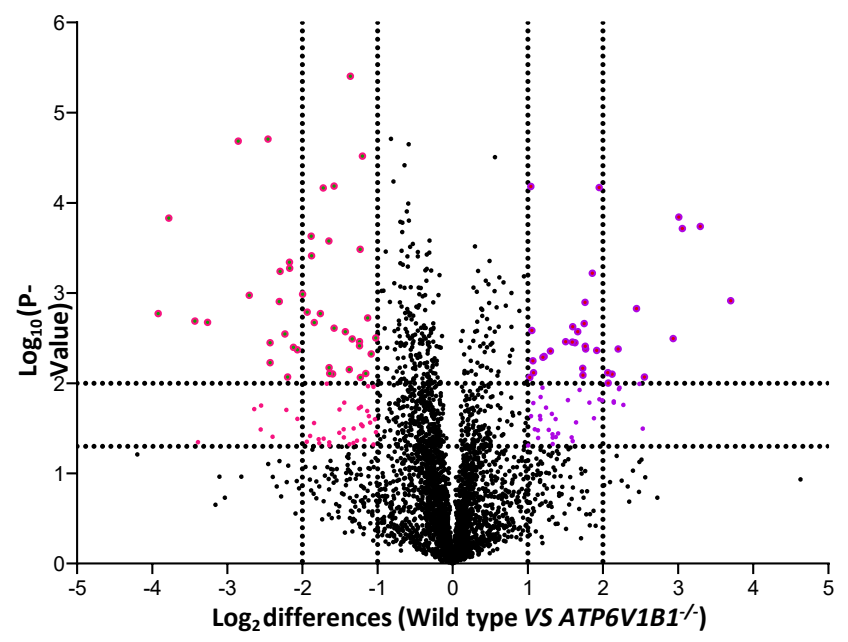

D

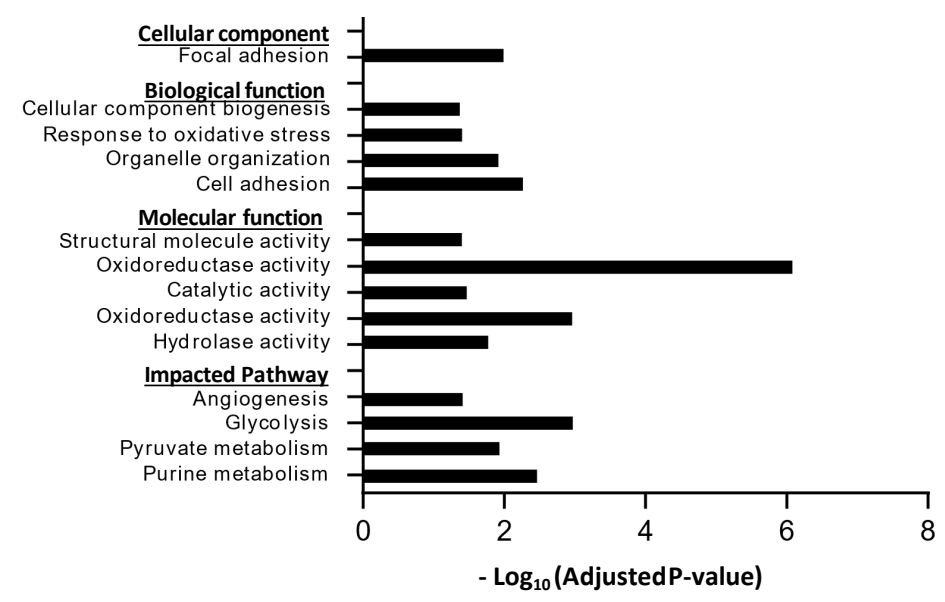

E
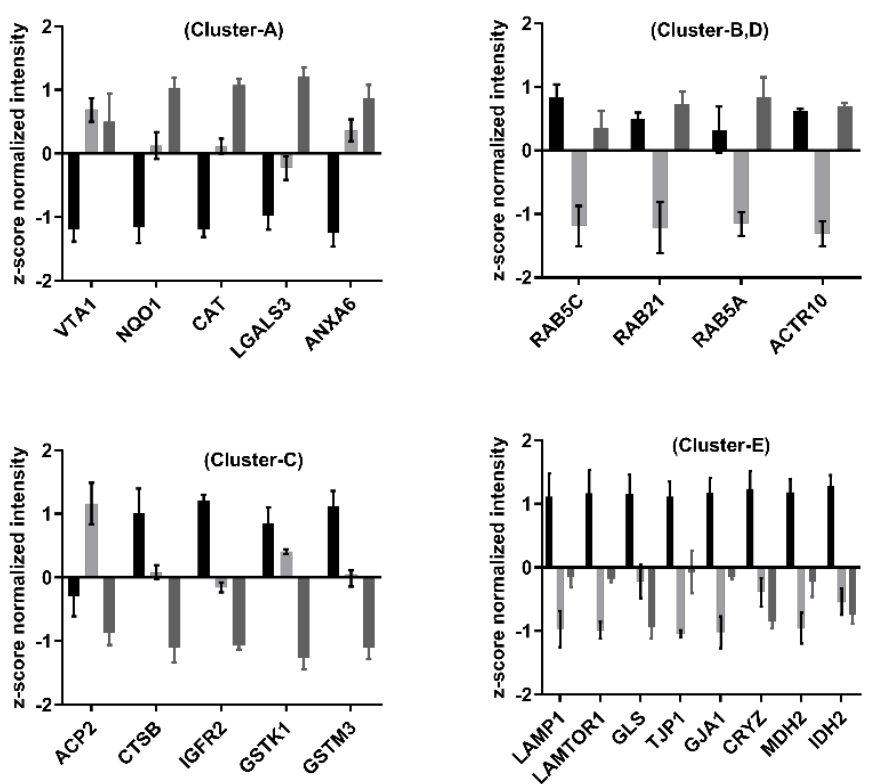

\section{Wild type $\quad$ ATP6V1B1 $^{-/}=$CTNS $^{-/}$}


Figure. 5

bioRxiv preprint doi: https://doi.org/10.1101/2020.07.24.219808; this version posted July 25, 2020. The copyright holder for this preprint (which was not certified by peer review) is the author/funder. All rights reserved. No reuse allowed without permission.

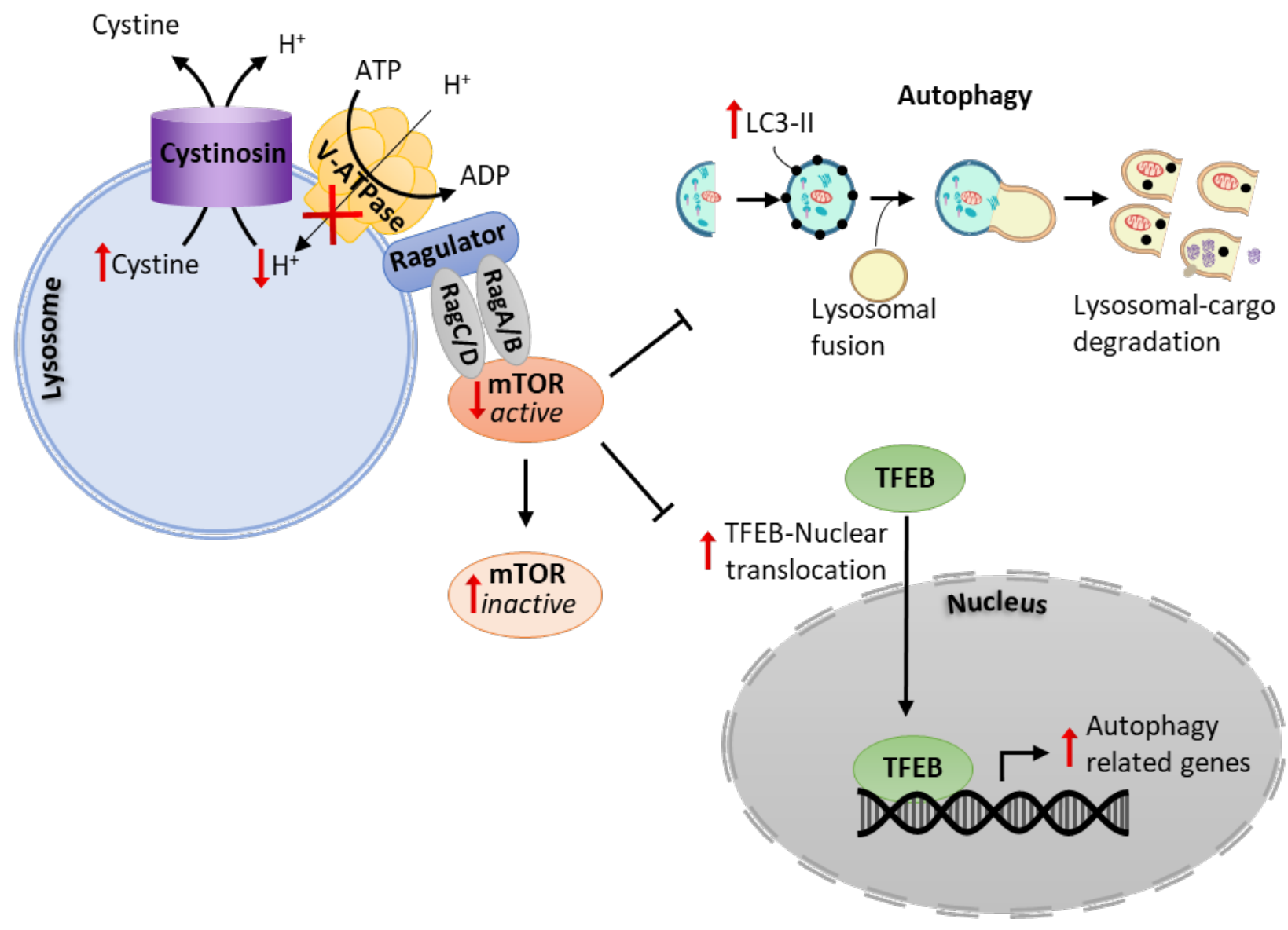


Supplementary figure S1

A bioRxiv preprint doi: https://doi.org/10.1101/2020.07.24.219808; this version posted July 25, 2020. The copyright holder for this preprint (which A was not certified by peer review) is the author/furBer. All rights reserved. No reuse allowed without permission.
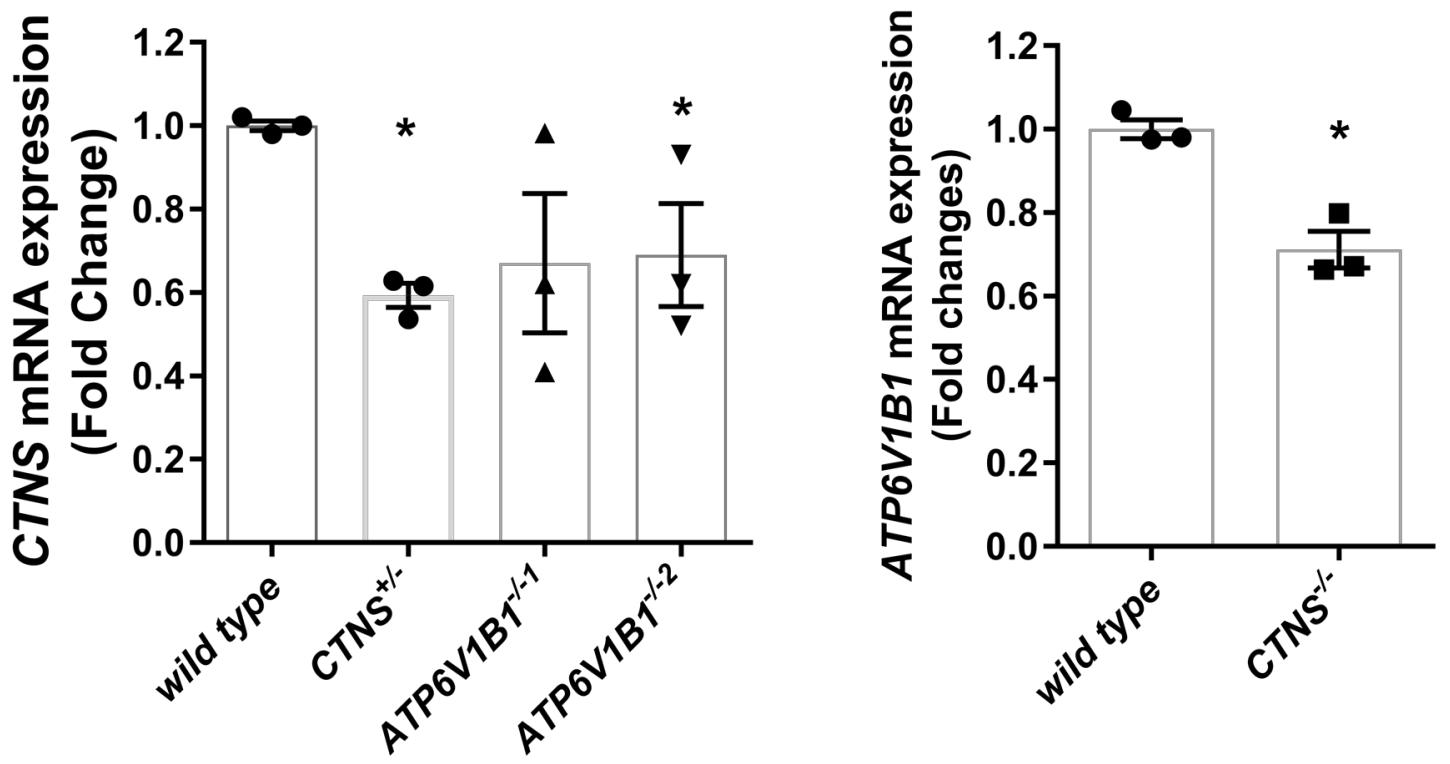